\title{
Functionalization-dependent effects of cellulose nanofibrils on tolerogenic mechanisms of human dendritic cells
}

This article was published in the following Dove Press journal: International Journal of Nanomedicine

\author{
Sergej Tomićl,2 \\ Nataša llićl \\ Vanja Kokol ${ }^{3}$ \\ Alisa Gruden-Movsesijan' \\ Dušan Mihajlović ${ }^{2}$ \\ Marina Bekićl \\ Ljiljana Sofronić- \\ Milosavljević \\ Miodrag Čolić'1,2,4 \\ Dragana Vučević \\ 'Institute for the Application of \\ Nuclear Energy, University of \\ Belgrade, Belgrade, Serbia; ${ }^{2}$ Institute \\ for Medical Research, Medical Faculty \\ of the Military Medical Academy, \\ University of Defense, Belgrade, \\ Serbia; ${ }^{3}$ Institute of Engineering \\ Materials and Design, University \\ of Maribor, Maribor, Slovenia; \\ ${ }^{4}$ Medical Faculty Foča, University \\ of East Sarajevo, Foča, Bosnia and \\ Herzegovina
}

Background: Cellulose nanofibrils (CNF) are attractive nanomaterials for various biomedical applications due to their excellent biocompatibility and biomimetic properties. However, their immunoregulatory properties are insufficiently investigated, especially in relation to their functionalization, which could cause problems during their clinical application.

Methods: Using a model of human dendritic cells (DC), which have a central role in the regulation of immune response, we investigated how differentially functionalized CNF, ie, native (n) CNF, 2,2,6,6-tetramethylpiperidine 1-oxyl radical-oxidized (c) CNF, and 3-aminopropylphosphoric acid-functionalized (APAc) CNF, affect DC properties, their viability, morphology, differentiation and maturation potential, and the capacity to regulate $\mathrm{T}$ cell-mediated immune response.

Results: Nontoxic doses of APAcCNF displayed the strongest inhibitory effects on DC differentiation, maturation, and $\mathrm{T}$ helper (Th) 1 and Th17 polarization capacity, followed by cCNF and nCNF, respectively. These results correlated with a specific pattern of regulatory cytokines production by APAcCNF-DC and their increased capacity to induce suppressive $\mathrm{CD} 8^{+} \mathrm{CD} 25^{+} \mathrm{IL}-10^{+}$regulatory $\mathrm{T}$ cells in immunoglobulin-like transcript (ILT)-3- and ILT-4dependent manner. In contrast, $\mathrm{nCNF}-\mathrm{DC}$ induced predominantly suppressive $\mathrm{CD} 4^{+} \mathrm{CD} 25^{\text {hi }} \mathrm{FoxP} 3^{\text {hi }}$ regulatory $\mathrm{T}$ cells in indolamine 2,3-dioxygenase-1-dependent manner. Different tolerogenic properties of CNF correlated with their size and APA functionalization, as well as with different expression of CD209 and actin bundles at the place of contact with CNF.

Conclusion: The capacity to induce different types of DC-mediated tolerogenic immune responses by functionalized $\mathrm{CNF}$ opens new perspectives for their application as well-tolerated nanomaterials in tissue engineering and novel platforms for the therapy of inflammatory $\mathrm{T}$ cellmediated pathologies.

Keywords: cellulose nanofibrils, biocompatibility, tolerogenic dendritic cells, regulatory T-cell subsets, immunomodulation

\section{Plain language summary}

Cellulose nanofibrils (CNF) display fascinating potential for application in biomedicine, and they are suitable for loading with different biomolecules, such as the osteogenesis-promoting phosphonates. Recently, our group showed that native CNF display an intrinsic potential to induce immune tolerance, thus lowering the possibility of adverse immune reactions upon implantation. However, it remained unknown as to how the modification of CNF with biomolecules may affect their immunomodulatory properties. Here, we showed that phosphonation of CNF enhances their capacity to induce anti-inflammatory and tolerogenic properties in human dendritic cells (DC), key cells controlling the immune response. The effects rely on a switch in tolerogenic mechanisms used by DC to spread tolerance via regulatory T-cell subsets. These results open new
Institute for the Application of Nuclear Energy, University of Belgrade, Banatska 3 I b, I I080 Belgrade (Zemun), Serbia

Tel +38 I II 2610126

Fax +38III 2618724

Email sergej.tomic@inep.co.rs
International Journal of Nanomedicine 2018:13 6941-6960 Dovepress in http://dx.doi.org/10.21 477/INN.S183510 (c) (1) (-) 2018 Tomic et al. This work is published and licensed by Dove Medical Press Limited. The full terms of this license are available at https://www.dovepress.com/terms.php cc) ${ }_{\mathrm{BY}} \mathrm{NC}$ and incorporate the Creative Commons Attribution - Non Commercial (unported, v3.0) License (http://creativecommons.org/licenses/by-nc/3.0/). By accessing the work you hereby accept the Terms. Non-commercial uses of the work are permitted without any further permission from Dove Medical Press Limited, provided the work is properly attributed. For permission for commercial use of this work, please see paragraphs 4.2 and 5 of our Terms (https://www.dovepress.com/terms.php). 
perspectives for the application of CNF, not only as well-tolerated scaffolds in tissue engineering and regenerative medicine, but also as a novel platform for a controlled DC-mediated induction of tolerogenic immune responses in immunotherapies of autoimmune diseases or allogenic transplantation.

\section{Introduction}

Research on the production of nanocellulose-based materials has significantly increased over the last few decades owing to their nanoscale dimensions and unique optical, electrical, magnetic, and mechanical properties, as well as biodegradability and nontoxicity. ${ }^{1}$ Cellulose nanofibrils (CNF) became highly attractive natural nanomaterials for biomedical applications. Thanks to their alternating crystalline and amorphous structures, physical properties of CNF resemble more to body nanofibers. ${ }^{2}$ In this sense, CNF have already been explored as scaffolds in tissue engineering, ${ }^{3}$ tridimensional matrices supporting cell growth, ${ }^{4}$ wound dressings,${ }^{5}$ and others. A specific surface chemistry of CNF enables the formation of hydrogels, long-lasting drug delivery systems, ${ }^{6}$ and engineered biomimetic surfaces, ${ }^{7}$ all of which allow their multifunctional application. ${ }^{8}$ Although recent studies confirmed the good biocompatibility of CNF, 9,10 their slow degradability in vivo ${ }^{11}$ could be a problem if the scaffold needs to be replaced gradually by a natural extracellular matrix. ${ }^{4}$ The oxidation of CNF was shown to be an efficient way of increasing their degradability, ${ }^{12}$ which also enables their functionalization with biomolecules. ${ }^{7}$ In line with this, we showed previously that 2,2,6,6tetramethylpiperidine 1-oxyl radical (TEMPO)-oxidized carboxylated-CNF (cCNF) can be functionalized efficiently with 3-aminopropylphosphoric acid (APA), to introduce phosphonate groups onto CNF-based scaffolds. Besides providing desirable porosity and mechanical properties, the phosphonation of CNF promoted osteogenic differentiation of mesenchymal stem cells, and increased $\mathrm{Ca}$ deposition and the formation of hydroxyapatite-like structures for bone tissue engineering. ${ }^{7}$ In addition to inducing a beneficial response in target tissue, a biomaterial should not elicit any adverse local or systemic reactions, especially those related to unwanted immune response. ${ }^{13}$ However, except for a few investigations on different cellulose-based materials, ${ }^{14-16}$ the immunological properties of native and functionalized CNF are largely unknown.

Key immune cells regulating the immune response, including the response to biomaterials and nanomaterials, are DC. ${ }^{17} \mathrm{DC}$ can recognize nanomaterials ${ }^{17,18}$ and respond by triggering proinflammatory/immunogenic or anti-inflammatory/tolerogenic immune response, depending on the nanomaterials' size, surface chemistry, charge, functional groups, and other parameters. ${ }^{17}$ Immunogenic DC are characterized by high expression of major histocompatibility complex and costimulatory molecules, and an increased production ratio of pro-inflammatory vs anti-inflammatory cytokines, particularly interleukin (IL)-12 p70/IL-10. ${ }^{19}$ This correlates with the increased capacity of DC to induce differentiation of T helper (Th) 1, Th17 cells, and cytotoxic CD8 ${ }^{+} \mathrm{T}$ lymphocytes, which are critically involved not only in fighting infections and tumors ${ }^{20}$ but also in graft destruction ${ }^{21}$ and autoimmune processes. ${ }^{22}$ In contrast, the induction of anti-inflammatory response and immune tolerance is mediated by DC with immature or semimatured phenotype, ${ }^{23}$ increased expression of co-inhibitory molecules, such as immunoglobulin-like transcript (ILT)-3 and ILT-4 molecules, and immunosuppressive factors, such as indolamine 2,3-dyoxigenase (IDO)-1, ${ }^{24}$ IL-10, IL-27, and transforming growth factor (TGF)- $\beta .^{25}$ These features were shown to be critical for the induction of regulatory $\mathrm{CD}^{+}$and $\mathrm{CD}^{+}{ }^{+} \mathrm{T}$-cell subpopulations, ${ }^{26}$ as well as for tolerogenic DCmediated suppression of autoimmune processes, ${ }^{27}$ increased transplant survival, ${ }^{28}$ and implant tolerance. ${ }^{29}$ Recent studies suggested that $\mathrm{CD}^{+}$Treg subpopulations may exhibit stronger suppressive capacity than the more familiar $\mathrm{CD}^{+}$ Treg subpopulations. ${ }^{30}$ However, it is still unknown which Treg subpopulation is involved predominantly in a particular DC-mediated tolerogenic immune response, and whether these processes can be manipulated precisely for DC-based therapy.

New approaches for the manipulation of DC functions came from the recently described intrinsic immunomodulatory properties of biomaterials and nanomaterials. ${ }^{25} \mathrm{We}$ discovered that $\mathrm{nCNF}$ are able to induce immunoregulatory cytokine profile in human peripheral blood mononuclear cells (PBMC) cultures. ${ }^{9}$ The effects correlated with the intrinsic capacity of $\mathrm{nCNF}$ to induce tolerogenic properties in human DC with a lower Th1/Th17-polarization capacity, and an increased capacity to induce anti-inflammatory $\mathrm{Th} 2$ cells and suppressive Treg cells. ${ }^{31}$ These properties of nCNF could be beneficial for scaffold tolerance, wound healing, and chronic inflammation therapies. ${ }^{31}$ However, it is not known as to how additional modification of $\mathrm{nCNF}$ through oxidation and functionalization with phosphonate groups modifies their cytocompatibility and DC-mediated immunomodulatory effects. Such investigations are prerequisite for the safe application of functionalized CNF, since unwanted stimulation or suppression of immune response may compromise their efficacy and induce adverse effects. The study objective was 
to compare the effects of $\mathrm{nCNF}$, cCNF, and APAcCNF on human DC phenotype and functions, as well as the mechanisms involved in CNF actions on DC and DC-mediated control of the immune response.

\section{Materials and methods}

\section{Synthesis and characterization of CNF}

Native CNF (nCNF, 20-50 nm thick and several $\mu \mathrm{m}$ long) were produced from bleached birch pulp and were obtained as $2.5 \mathrm{wt} \%$ water dispersion (Betulium Ltd., Espoo, Finland). ${ }^{7}$ Oxidized (carboxylated) CNF (cCNF, 3-5 nm thick and $500-2,000 \mathrm{~nm}$ long; bearing $1.3 \pm 0.1 \mathrm{mmol} / \mathrm{g}$ of carboxylic groups) were prepared by TEMPO-oxidation of native $\mathrm{CNF}^{12}$ as $1.14 \mathrm{wt} \%$ water dispersion (Betulium Ltd.), and used for further functionalization with APA (Sigma-Aldrich Co., St Louis, MO, USA). The APA molecules were coupled to cCNF under heterogeneous conditions, using carbodiimide chemistry to produce APA-functionalized (APAc) CNF (0.5 wt \%). Briefly, APA (17.5 mg) was suspended in $4 \mathrm{~mL}$ of Milli-Q water, prior to mixing with $25 \mathrm{~mL}$ of $0.5 \% \mathrm{w} / \mathrm{v}$ of cCNF dispersion in $0.05 \mathrm{M} 2-(\mathrm{N}$ morpholino) ethanesulfonic acid buffer, corresponding to a 1:1 $\mathrm{M}$ ratio between the carboxylic groups of cCNF and amino groups of APA ( $0.5 \mathrm{wt} \%$ in water). Carboxylic groups of cCNF were activated with 1-ethyl-3 (3-dimethylaminopropyl)-1 - carbodiimide hydrochloride and $\mathrm{N}$-hydroxy succinimide in 10:1 $\mathrm{M}$ ratio to the carboxylic groups, and the dispersion was incubated at room temperature for 24 hours under mild shaking conditions, followed by a complete dialysis through cellulose membrane of $1 \mathrm{kDa}$ cutoff. All CNF and APA samples were characterized as described previously, ${ }^{7}$ and sterilized in sealed glass tubes in an autoclave at $121^{\circ} \mathrm{C}$ for 15 minutes, and then sonicated for 15 minutes prior to use. For the transmission electron microscopy (TEM) analysis, $\mathrm{nCNF}, \mathrm{cCNF}$, and APAcCNF were centrifuged in PBS, fixed with $2 \%$ glutaraldehyde, and post-fixed in $1 \% \mathrm{OsO}_{4}$. After dehydration in graded alcohols, thin sections were embedded in Epon 812 and analyzed by TEM (Morgagni 268D). The concentration of phosphates in APAcCNF, corresponding to the concentration of APA attached to cCNF, was determined by ion liquid chromatography according to ISO 10304-1:2007. ${ }^{32}$ Additionally, phosphates were determined by the colorimetric UV method as described earlier, ${ }^{33}$ using a UV-vis Shimadzu 1700A spectrophotometer (Duisburg, Germany).

\section{Cells and cultures}

All experiments and protocols involving human blood samples were approved by the Ethical Board of the Military Medical Academy, University of Defense (MMA), and carried out in accordance with the MMA Guidelines. PBMC were obtained from buffy coats of healthy volunteers, who signed informed consent in accordance with the Declaration of Helsinki, using density gradient centrifugation on lymphocyte separation medium 1077 (PAA, Linz, Austria). Monocytes, CD3 ${ }^{+}$T cells, and $\mathrm{CD}^{+} \mathrm{T}$ cells were isolated from PBMC with magneticactivated cell sorting (MACS) of untouched cell populations, using the monocyte iolation kit II, pan T cell isolation kit, and $\mathrm{CD}^{+} \mathrm{T}$ isolation kit (Miltenyi Biotec, Bergisch Gladbach, Germany), respectively. The purity of CD $14^{+}$monocytes, $\mathrm{CD}^{+}$ and $\mathrm{CD}^{+} \mathrm{T}$ cells was higher than $90 \%$, as evaluated by flow cytometry (Cube 6; Sysmex Partec GmbH, Görlitz, Germany). HEp-2 larynx epidermoid carcinoma cells were obtained from the American Type Culture Collection (Rockwell, MD, USA) and cultivated in complete Roswell Park Memorial Institute (RPMI)-1640 medium containing 10\% fetal calf serum (FCS), $50 \mu \mathrm{M}$ 2-mercaptoethanol (all from Sigma-Aldrich Co.), and $1 \%$ streptomycin, gentamicin, and penicillin (ICN Galenika, Belgrade, Serbia) at $37^{\circ} \mathrm{C}, 90 \%$ humidity, and $5 \% \mathrm{CO}_{2}$.

Monocytes $\left(1 \times 10^{6} / \mathrm{mL}\right)$ were cultivated in CellGenix ${ }^{\circledR}$ GMP Dendritic Cell Medium (CellGenix, Freiburg, Germany) supplemented with $100 \mathrm{ng} / \mathrm{mL}$ of human recombinant granulocyte macrophages colony stimulating factor (GM-CSF; Novartis, Basel, Switzerland) and $20 \mathrm{ng} / \mathrm{mL}$ of human recombinant IL-4 (Roche Diagnostics, Basel, Switzerland). Monocytes were cultured either in the presence of $\mathrm{nCNF}$, cCNF, APAcCNF $(250-500 \mu \mathrm{g} / \mathrm{mL})$, soluble APA at the concentrations equivalent to the amount attached to APAc$\mathrm{CNF}$, or in their absence (control DC) for 4 days. Prior to use in cell cultures, CNF samples were pre-diluted in CellGenix medium and $\mathrm{pH}$ was adjusted to 7.2 with $\mathrm{NaOH}$ and $\mathrm{HCl}$. After 4 days of cultivation with $\mathrm{CNF}$, the cultures were either treated with $500 \mathrm{ng} / \mathrm{mL}$ of lipopolysaccharide (LPS) from Escherichia coli 0.111:B4 (Sigma-Aldrich Co.) and $50 \mathrm{ng} / \mathrm{mL}$ of interferon (IFN)- $\gamma$ (R\&D Systems, Minneapolis, MN, USA), or left untreated for the next 16 hours. In some experiments, anti-IL-6 receptor $(\mathrm{R})$ (tocilizumab [Actemra ${ }^{\circledR}$; Roche Diagnostics], $20 \mu \mathrm{g} / \mathrm{mL}$ ) and/or IL-6 (40 ng/mL; R\&D systems) were added during differentiation of DC, as described in the "CNF differently impair differentiation and subsequent maturation of DC" section.

\section{Mixed cell cultures}

Before cocultivation experiments with T cells, DC were filtered through sterile $30 \mu \mathrm{m}$ pore-size filters (Miltenyi Biotec) and washed twice in complete RPMI medium to prevent transfer of free CNF and stimuli. DC $\left(0.25 \times 10^{4}-0.5 \times 10^{4} /\right.$ well in 96-well plate) were cocultivated with MACS-purified 
allogeneic $\mathrm{T}$ cells $\left(1 \times 10^{5} /\right.$ well) for 5 days. For proliferation assays, $\mathrm{CD}^{+} \mathrm{T}$ cells were pre-labeled with carboxyfluorescein succinimidyl ester (CFSE, $2 \mu \mathrm{M}$; Thermo Fisher Scientific, Waltham, MA, USA), according to the manufacturer's protocol. For cytokines' analysis, the supernatants of DC/CD3 ${ }^{+}$ T-cell cocultures were collected after addition of phorbolmyristate acetate (PMA) $(20 \mathrm{ng} / \mathrm{mL})$ and ionomycin $(500 \mathrm{ng} /$ $\mathrm{mL}$ ) (both from Sigma-Aldrich Co.) for the last 4 hours of incubation. For the flow cytometric detection of intracellular cytokines, the cocultures were treated with PMA/ionomycin and monensin ( $3 \mu \mathrm{M}$; Sigma-Aldrich Co.) for the last 3 hours of incubation. In some experiments, $\mathrm{CD}^{+}$or $\mathrm{CD}^{+} \mathrm{T}$ cells $\left(5 \times 10^{5} /\right.$ well in a 24 -well plate) were primed for 3 days with DC $\left(1 \times 10^{4} /\right.$ well $)$, either in the presence or absence of 1-methyl-tryptophan (1-MT, $0.3 \mathrm{mM}$; Sigma-Aldrich Co.), anti-ILT-3, and anti-ILT-4 antibody (Ab) (both at $2 \mu \mathrm{g} / \mathrm{mL}$; R\&D Systems) or isotype control Ab (anti-rat IgG2b; Thermo Fisher Scientific), and then treated with IL-2 (3 ng/mL; R\&D Systems) for an additional 3 days. Additional control included the $\mathrm{T}$ cells cultivated likewise, but in the absence of DC. The primed T cells were analyzed phenotypically or used in the suppression assay in which different numbers of primed $\mathrm{T}$ cells $\left(0.5 \times 10^{5}-1 \times 10^{5} /\right.$ well in a 96 -well plate) were cocultivated with responder allogeneic CFSE-labeled $\mathrm{CD}^{+} \mathrm{T}$ cells $\left(2 \times 10^{5} /\right.$ well $)$ in the presence of plate-bonded anti-CD3 $(5 \mu \mathrm{g} / \mathrm{mL}) \mathrm{Ab}$ and soluble anti-CD28 Ab $(1 \mu \mathrm{g} /$ $\mathrm{mL}$ ) (both from eBioscience, San Diego, CA, USA) for 5 days. The cytotoxic activity of $\mathrm{CD} 8^{+} \mathrm{T}$ cells $\left(0.5 \times 10^{5}\right.$ cells/ sample) primed with HEp-2 lysate-pulsed syngeneic DC was evaluated by their co-incubation with CFSE-labeled HEp-2 target cells $\left(1 \times 10^{5}\right.$ cells/sample) for 4 hours, as described previously. ${ }^{34} \mathrm{PBMC}\left(10 \times 10^{6} / \mathrm{mL}\right)$ were cryopreserved in $10 \%$ dimethyl-sulfoxide/FCS at $-80^{\circ} \mathrm{C}$ for 5 days, and used for the isolation of syngeneic $\mathrm{CD} 8^{+} \mathrm{T}$ cells on day of cocultivation with HEp-2 lysate-pulsed DC. The viability of $\mathrm{CD} 8^{+} \mathrm{T}$ cells after the thawing of PBMC and MACS sorting was more than 95\%, according to Trypan blue exclusion test.

\section{Cell viability, proliferation, and cytokine production}

The analysis of DC viability after 4 days of cultivation with or without CNF and APA samples was done after staining the cells with Trypan blue (1\% in physiological solution), or propidium iodide (PI, $10 \mu \mathrm{g} / \mathrm{mL}$; Sigma-Aldrich Co.), as described earlier. ${ }^{34} \mathrm{HEp}-2$ cell death in coculture with DC-primed $\mathrm{CD}^{+} \mathrm{T}$ cells was analyzed by flow cytometry (Sysmex Partec Cube 6) based on PI staining of CFSE-labeled HEp-2 cells. The proliferation of CFSE-labeled CD $3^{+} \mathrm{T}$ cells in response to $\mathrm{DC}$, or $\mathrm{CD} 3 / \mathrm{CD} 28$ stimulation, was analyzed within $\mathrm{PI}^{-}$population by flow cytometric measurement of CFSE dilution during cell division. ${ }^{34}$ The Proliferation Index, ie, the average number of cells derived from an initial cell, was calculated using proliferation fit statistics in FCS Express 4 (De Novo Software, Glendale, CA, USA). The cytokine concentrations in cell culture supernatants were determined by appropriate enzyme-linked immunosorbent assay (ELISA) kits (R\&D Systems).

\section{Flow cytometry}

Phenotype analysis of DC and T cells after the cultures was carried out using flow cytometer (Sysmex Partec Cube 6) after staining the cells by using the following Abs (Clone) and reagents: immunoglobulin (Ig) G1a negative controlbiotin (MCA928), IgG1 negative control-phycoerythrin (PE) (MCA928PE), IgG1 negative control-fluorescein isothiocyanate (FITC) (MCA928F), anti-CD1a-PE-Cy5 (NA1/34HLK) (all from Serotec, Oxford, UK), anti-human leukocyte antigen (HLA)-DR-biotin (LN3), IgG1a negative control-PECy5 (P.3.6.2.8.1), anti-CD86-PE (IT2.2), streptavidin-PECy5, anti-CD4-PECy5 (RPA-T4), anti-IL-4-PE (8D4-8), antiILT3-PE (ZM4.1), anti-ILT-4-PE (42D1), anti-TGF- $\beta$-biotin (eBio16TFB), anti-CD25-PE, anti-CD25-PECy5 (BC96), anti-forkhead box (Fox) P3-FITC (PCH101), anti-IL-10PE (JES5-16E3), anti-CD39-FITC (A1), anti-CD8-PEcy5 (RPA-T8), anti-cytotoxic T-lymphocyte-associated protein (CTLA)-4-PE (14D3) (all from eBioscience), streptavidinAlexa 488, anti-mouse IgG-Alexa 488, anti-CD1a-PE (HI149) (all from Biolegend, San Diego, CA, USA), anti CD40-allophycocyanin (APC) (5C3), anti-IL-12 (p40/ p70)-PE (C11.5) (all from BD Pharmingen, San Diego, CA, USA), anti-CD83-FITC (HB15e), anti-IFN- $\gamma$-FITC (25723), anti-IL17-peridinin-chlorophyll-protein complex conjugate (PerCP) (41802), anti-IL-10-FITC (127107), anti-HLA-DR PerCP (L243), anti-CD4-FITC, anti-CD4-PerCP (11830), anti-IDO-1-APC (700838) (all from R\&D Systems), anti-CD14-FITC (TUK4), IgG1 negative control-PerCP (IS521F5) (Miltenyi Biotec), anti-CD4-PE (MEM-241) (Partec Sysmex). Surface staining with primary Abs was conducted in $\mathrm{PBS} / 0.1 \% \mathrm{NaN}_{3} / 0.5 \% \mathrm{FBS}$ prior to intracellular staining that was carried out using the flow cytometry fixation and permeabilization kit (R\&D Systems). ${ }^{31,34}$ The gates for cultivated DC and T cells were set according to their specific forward scatter (FS) and side scatter (SS) properties, thereby avoiding dead cells with low FS/SS signal. The gates, containing more than $97 \%$ of live cells, were confirmed by independent $\mathrm{PI}^{+}$staining of non-permeabilized cells. Signal overlap 
between the fluorescent channels was compensated before each experimental analysis using single labeled samples. Nonspecific fluorescence was determined by using the appropriate isotype control Abs and fluorescence minus one controls.

\section{Analysis of DC-CNF interactions}

The internalization of CNF by DC was assessed by flow cytometry, wherein the internal granularity of DC was analyzed by monitoring the SS parameter, as described earlier. ${ }^{31,34}$ Additionally, light and epi-fluorescent microscopy analyses (Nikon Eclipse 55i, Tokyo, Japan) were carried out to assess the interaction of DC with the CNF samples. The cells were collected from the cultures without filtration and the cytospins were prepared at $500 \mathrm{rpm}$ for 5 minutes. The cells were stained with May-Grunwald Giemsa for light microscopy analysis. For epi-fluorescent microscopy, the slides were stained with anti-CD209, followed by anti-mouse IgG-Alexa 488 for analysis with green filter set (B-2A, ex: 450-490 nm, DM 505, BA 520). Actin filaments were stained with phalloidin rhodamine $(0.16 \mu \mathrm{M}$; Thermo Fisher Scientific), according to the manufacturer's protocol and monitored with red filter set (G-2A, ex: 510-560 nm, DM 575, BA 590). After that, the samples were stained with calcofluor white (Sigma-Aldrich Co.), as described earlier, ${ }^{31}$ and DAPI $(40 \mu \mathrm{g} / \mathrm{mL}$; SigmaAldrich Co.) simultaneously, and monitored with UV filter set (UV-2B, ex: 330-380 nm, DM 400, BA 435). The images taken by each filter set were acquired in red-green-blue (RGB) format, and the channels were separated offline in ImageJ software (National Institutes of Health, Bethesda, MD, USA). The images acquired under UV filter set contained a green component (DAPI-stained nuclei) and a blue component (calcofluor-stained CNF, cytoplasm, and nuclei), so they were analyzed and presented as separate channels. Accumulation of actin and CD209 at the place of contact with CNF was quantified by measuring the fold change of mean gray values in red and green channels, respectively, in the regions of DCCNF contact against the cytoplasmic part of the same cell, for a total of $15-25$ cells per CNF treatment. Raw images are accessible upon request from the authors.

\section{Statistical analysis}

The results are presented as representative data or mean \pm SD values of at least three independent experiments. The differences between treatments were analyzed by repeated measures (RM) ANOVA with Tukey's multiple comparison test using GraphPad Prism software (GraphPad, La Jolla, CA, USA). All tests were two-sided with the significance level of $P=0.05$.

\section{Results CNF properties}

Native CNF, cCNF, and APAcCNF size and dispersity were determined as described previously. ${ }^{7,9,31}$ The analysis of vibration bands within cCNF and APAcCNF by Fourier transform infrared spectroscopy confirmed the formation of covalent amide bonds between amino groups of APA and carboxylic groups of cCNF, rather than APA adsorption on cCNF. ${ }^{7}$ TEM investigation confirmed that TEMPO-oxidation of nCNF, besides homogenization and dispersion, also reduced the length of nanofibrils (Figure S1). Moreover, it seems that APA functionalization of $\mathrm{cCNF}$ additionally dispersed the nanofibrils, although it did not alter their size significantly. ${ }^{7}$ Measurements of surface charge by potentiometric titration showed that oxidation increased the concentration of negative surface charge significantly due to the presence of carboxylic groups (from $0.034 \pm 0.001 \mathrm{mmol} / \mathrm{g}$ to $1.3 \pm 0.1 \mathrm{mmol} / \mathrm{g}$ ) and its reduction to $0.5 \pm 0.01 \mathrm{mmol} / \mathrm{g}$ after APA functionalization. ${ }^{7}$ Considering that negative surface charge may come from free carboxylic groups, as well as from phosphate groups, we determined the concentration of phosphates in APAcCNF directly. Both the ion liquid chromatography method ${ }^{32}$ and the UV method suggested that $10.9 \% \pm 1.1 \%$ of phosphates are present in APAcCNF, whereas phosphate levels in $\mathrm{nCNF}$ and $\mathrm{CCNF}$ were not detectable. Since all methods suggested that about $11 \mathrm{wt} \%$ of APA is attached to APAcCNF, the corresponding concentrations of soluble APA were used in cell culture experiments.

\section{CNF affect DC morphology}

To study the immunomodulatory actions of CNF, we used a model of human monocytes-derived DC. Therefore, MACSsorted $\mathrm{CD} 14^{+}$blood monocytes were cultured in the presence of GM-CSF/IL-4 for 4 days, which led to differentiation of immature CD209-expressing DC..$^{31,35}$ Native CNF, cCNF, APAcCNF, and equivalent concentrations of soluble APA were added to GM-CSF/IL-4-treated monocytes on day 0 . To exclude the possibility that the immunomodulatory effects of CNF are due to cytotoxicity, the viability of DC after 4 days of cultivation was evaluated first. The Trypan blue exclusion test suggested that $500 \mu \mathrm{g} / \mathrm{mL}$ of APAcCNF lowered DC viability significantly, by $27 \% \pm 8 \%$, unlike the sample concentration of $\mathrm{nCNF}, \mathrm{cCNF}$, and the corresponding concentration of soluble APA $(55 \mu \mathrm{g} / \mathrm{mL})$ (Figure 1A). This was confirmed by flow cytometric analysis of the cells stained with PI/PBS (data not shown). In contrast, neither of the investigated CNF samples had significant effects on DC viability at the concentration of $250 \mu \mathrm{g} / \mathrm{mL}$, so 
A

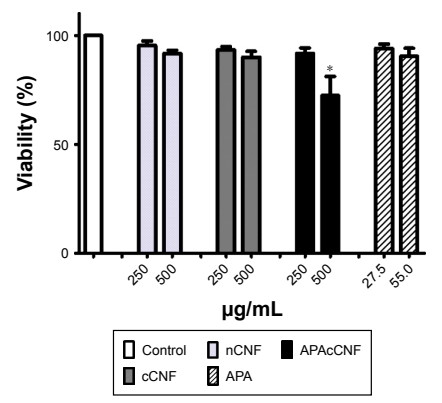

B

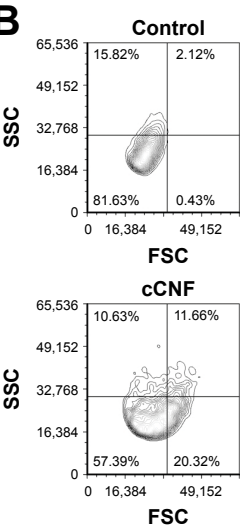

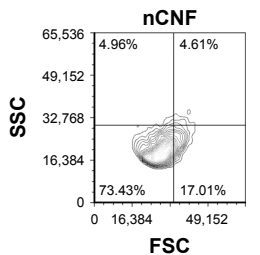

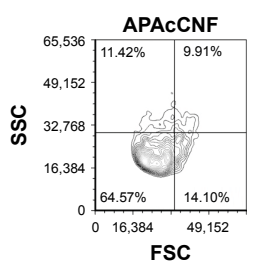

cCNF

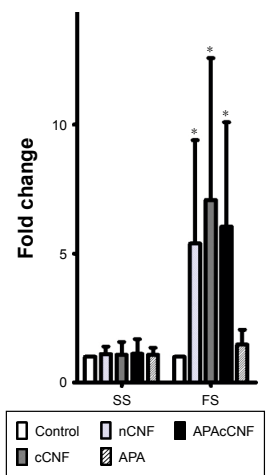

APACCNF

C

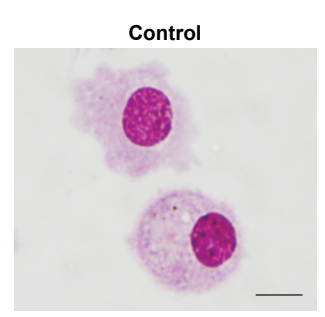

nCNF
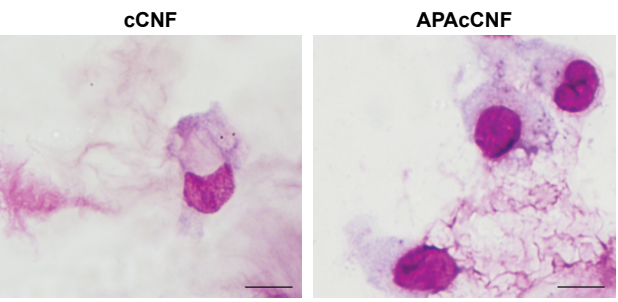

D
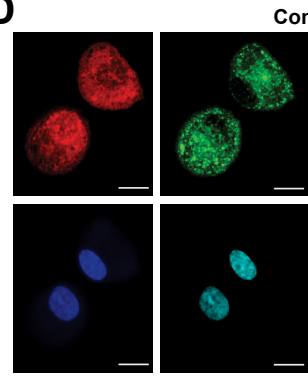

Control
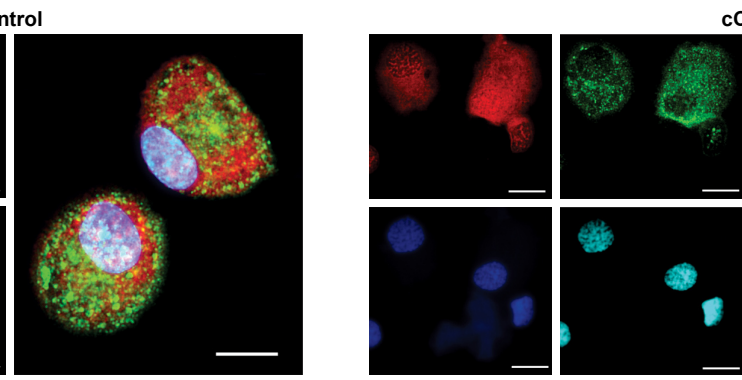

cCNF

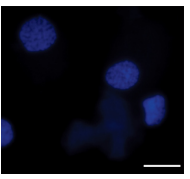

nCNF
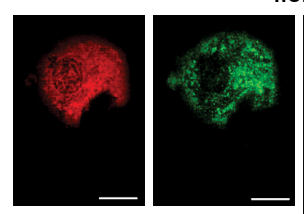

NF
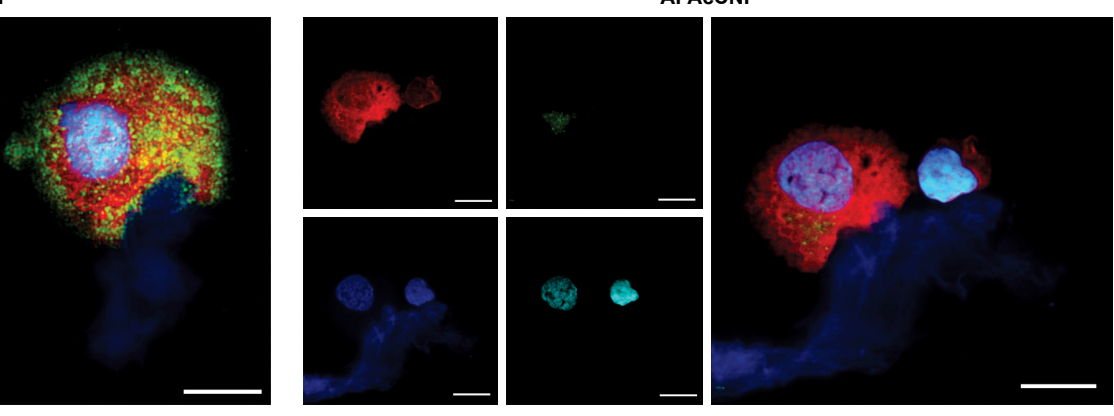

E
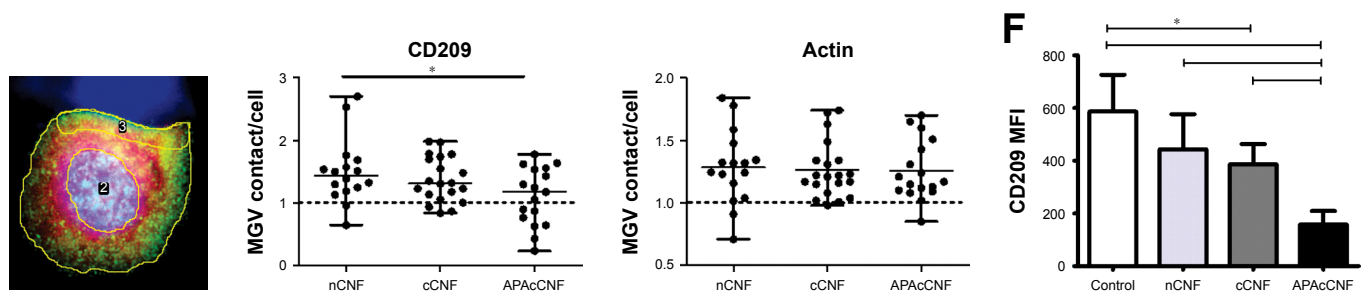

Figure I Effects of CNF samples on viability and morphology of DC.

Notes: (A) Viability of DC after the culture with CNF samples relative to control DC (I00\%). (B) A representative flow cytometry analysis of SSC/FSC, and the summarized data from seven experiments with different donors are shown as fold change of control DC \pm SD. (C) MGG-stained DC collected after the cultures with CNF. (D) Epi-fluorescent images of CNF-treated DC after staining with phalloidin rhodamine-actin (red), anti-CD209-IgG Alexa 488 (green), calcofluor white-CNF (dark blue), and DAPI-nuclei (light blue). Scale bars represent $10 \mu \mathrm{m}$. (E) Fluorescence intensity (CD209 and actin) in the contact area with nCNF (3) against the cytoplasmic part of the cells (whole cell excluding nucleus [2]) was calculated as MGV relative to control DC, and the data for each cell measured in one experiment are shown with indicated median and range statistics. (F) The surface expression of CD209 on DC, as determined by flow cytometry. The results are shown as mean MFI \pm SD of three independent experiments. (C, D) Image scale bars represent I0 $\mu$ m. (E, F) $* P<0.05$ compared to control, or as indicated (RM ANOVA with Tukey's post-test).

Abbreviations: APA, 3-aminopropylphosphoric acid; APAc, APA-functionalized; c, carboxylated; CNF, cellulose nanofibrils; DC, dendritic cells; FSC, forward scatter; MFI, mean fluorescence intensity; MGG, May-Grunwald Giemsa; MGV, mean gray value; n, native; RM, repeated measures; SSC, side scatter. 
further experiments were carried out with nontoxic doses of $250 \mu \mathrm{g} / \mathrm{mL}$ of CNF samples and $27.5 \mu \mathrm{g} / \mathrm{mL}$ of APA.

Next, we assessed the changes in DC morphology after their differentiation with nontoxic doses of CNF samples. As a common method for the evaluation of nanoparticle internalization, ${ }^{31,34,36}$ we monitored the granularity of DC according to their SS properties. It was found that the granularity of DC differentiated with CNF samples was insignificantly modified compared to the untreated control DC (Figure 1B). In contrast, DC differentiated with CNF samples, but not soluble APA, showed an increase in their FS properties (ie, size) significantly, which suggested that CNF were not internalized significantly, but rather acted on the cell surface. The MGG-stained preparation confirmed that DC interacted closely with CNF via many extended processes and membrane invaginations. It appeared that $\mathrm{DC}$ were trying to internalize CNF, but the majority of nanofibers were just too long (Figure 1C), so the process resembled frustrated phagocytosis. Our previous study suggested that CD209 was directly involved in interaction between $\mathrm{DC}$ and $\mathrm{nCNF} .{ }^{31}$ The epi-fluorescent microscopy, indeed, showed a redistribution of CD209 expression in contact with $\mathrm{nCNF}$ as well as cCNF samples. CD209 expression, as well as the actin expression, was increased significantly at the place of contact with these CNF (Figure 1D and E). Although the actin expression was increased at the place of contact with APAcCNF, the expression of CD209 by these DC was severely downregulated (Figure 1E), which was confirmed by flow cytometry as well (Figure 1F). The lack of CD209 expression on DC differentiated in the presence of APAcCNF suggested their severely impaired differentiation pattern.

\section{CNF differently impair differentiation and subsequent maturation of DC}

GM-CSF/IL-4-induced differentiation of DC correlates with a complete downregulation of CD14 expression and upregulation of CD1a after 4 days of cultivation. ${ }^{34}$ After the differentiation in the presence of CNF samples, DC indeed displayed a significantly altered differentiation pattern. For instance, both control DC and those differentiated in presence of soluble APA downregulated CD14 completely and upregulated CD1a (Figure 2A and B). nCNF and cCNF impaired the upregulation of CD1a on DC significantly, without affecting downregulation of CD14. In contrast, DC differentiated with APAcCNF expressed the highest levels of CD14 and the lowest levels of CD1a compared to all other DC.

To assess the maturation potential of DC differentiated with CNF, a strong type 1-inducing inflammatory cocktail,
LPS and IFN- $\gamma,{ }^{37}$ was added on day 4 , for the next 16 hours. Flow cytometry analysis showed that without LPS/IFN- $\gamma$ stimulation, the expression of CD83, CD86, HLA-DR, and CD40 on all treated DC were similar to that on non-treated control DC, ie, they contained the immature phenotype (Figure 2C). LPS/IFN- $\gamma$ stimulation induced a strong upregulation of all tested markers on the control DC, as expected. ${ }^{34,37}$ However, the upregulation of CD83, HLA-DR, and CD40 on DC differentiated in the presence of $\mathrm{nCNF}$ and $\mathrm{cCNF}$ was significantly lower compared to the control LPS/IFN- $\gamma$ stimulated DC. In this sense, APAcCNF displayed the strongest inhibitory effect, including the expression of costimulatory CD86 molecule. DC differentiated with soluble APA had a lower upregulation capacity of HLA-DR after the LPS/IFN- $\gamma$ treatment, but not other examined markers, as compared to the corresponding control DC.

In addition to surface markers, DC mediate the polarization of T-cell differentiation via different cytokines. ${ }^{20}$ IL-12/IL-10 production ratio by DC was shown as a good indicator of their Th polarization capacity. ${ }^{19}$ The intracellular analysis of IL-12p40/p70 and IL-10 in DC by flow cytometry suggested that nCNF reduced IL-12/IL-10 expression ratio in LPS/IFN- $\gamma$-stimulated DC significantly, whereas cCNF and APAcCNF displayed such an effect in non-stimulated DC as well. Soluble APA did not change significantly the IL-12/IL-10 ratio in DC (Figure 2D). The measurements of the secreted IL-12p70 and IL-10 products in DC culture supernatants by ELISA confirmed such findings (Figure 2E).

The analysis of other DC cytokines in cell culture supernatants showed that $\mathrm{nCNF}$ did not modulate their production by immature DC (Figure 2E). After LPS/IFN- $\gamma$ stimulation, nCNF-DC displayed an increased capacity to produce TGF- $\beta$, and a lower capacity to produce IL-23, IL-27, and IL-6 compared to the corresponding control DC. Immature DC differentiated with cCNF produced somewhat higher levels of IL-6, and lower levels of IL-23, IL-27, and IL-6 upon LPS/IFN- $\gamma$-induced maturation, whereas TGF- $\beta$ production was not affected. Immature APAcCNF-DC produced significantly higher levels of TGF- $\beta$, IL-27, and IL- 6 compared to the control immature DC. After LPS/IFN- $\gamma$ treatment, those cells still displayed an increased capacity to produce IL-27 and TGF- $\beta$, and a diminished capacity for IL-23 production, whereas their capacity to produce IL-6 was similar to the corresponding control LPS/IFN- $\gamma$-stimulated DC.

Frustrated phagocytosis of fibrillar nanomaterials was shown to correlate with increased IL- 6 expression, ${ }^{38}$ and IL-6 alone can shift GM-CSF/IL-4-induced differentiation of 
A
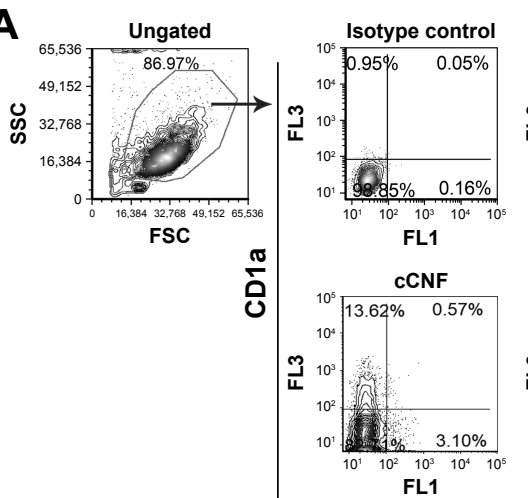
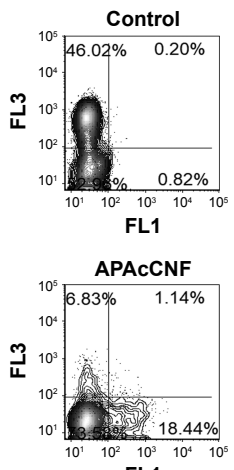

FL1
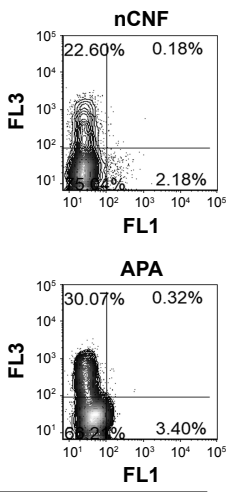

B

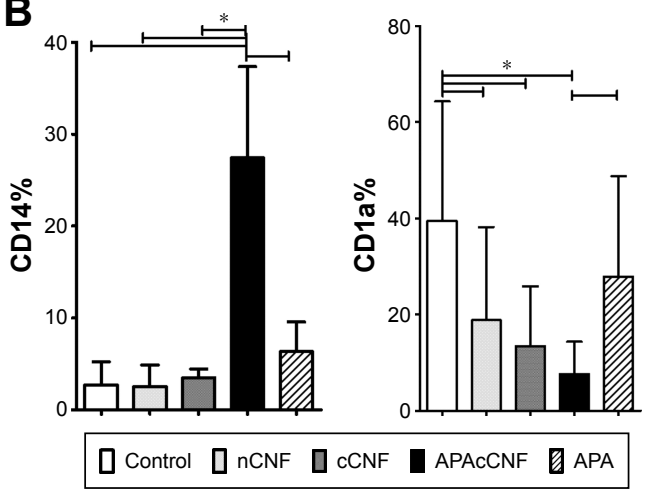

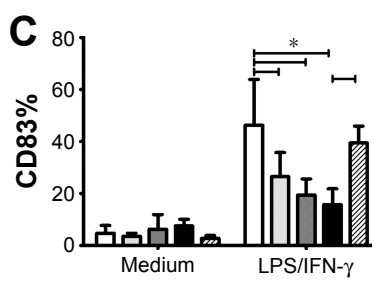
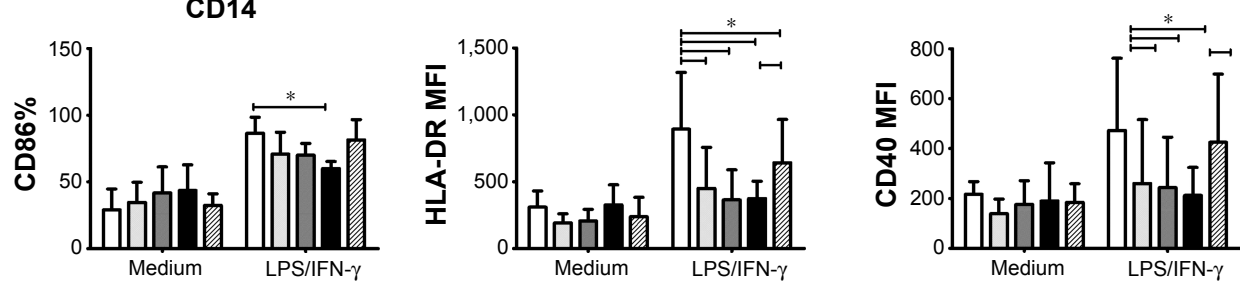

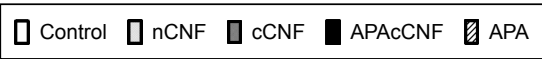

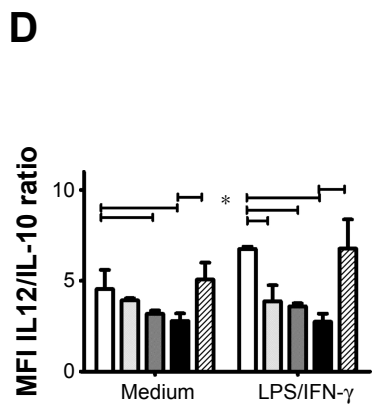

E
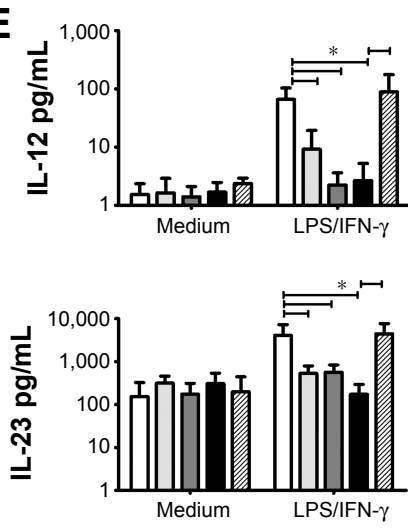
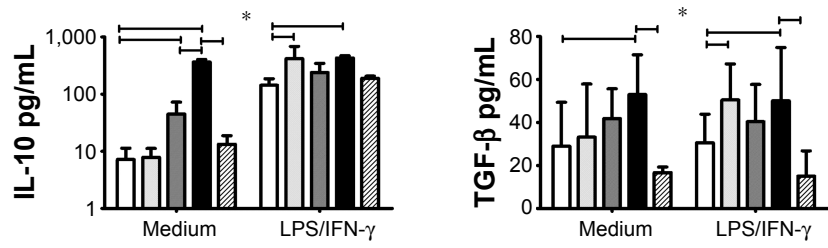

Q Control D nCNF D CCNF APACCNF G APA
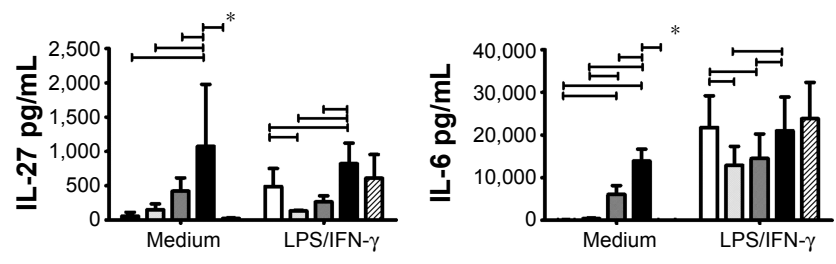

Figure 2 Effects of CNF samples on DC differentiation, maturation, and cytokines production.

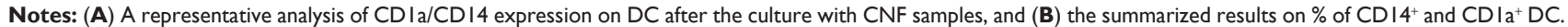
(C, D) The phenotypic analysis of DC 16 hours after LPS/IFN- $\gamma$ stimulation or without stimulation (medium) for the indicated surface markers (C) or intracellular cytokines (D) is shown. (E) The levels of cytokines in DC culture supernatants as determined by ELISA. The data from seven (B-D) or five (E) independent experiments with different DC donors are presented as mean \pm SD. $* P<0.05$ as indicated (RM ANOVA Tukey's post-test).

Abbreviations: APA, 3-aminopropylphosphoric acid; APAc, APA-functionalized; c, carboxylated; CNF, cellulose nanofibrils; DC, dendritic cells; FSC, forward scatter; HLA, human leukocyte antigen; IFN, interferon; LPS, lipopolysaccharide; MFI, mean fluorescence intensity; n, native; RM, repeated measures; SSC, side scatter; TGF, transforming growth factor.

monocytes toward CD14+ macrophage-like cells. ${ }^{39}$ Therefore, we wondered whether the blockage of IL-6-mediated effects could recover the differentiation and maturation of DC differentiated in the presence of APAcCNF. Although anti-IL6R Ab (tocilizumab, $20 \mu \mathrm{g} / \mathrm{mL}$ ) could block completely the effects of exogenous IL-6 (40 ng/mL) (data not shown), the differentiation and subsequent maturation of $\mathrm{DC}$ in the presence of tocilizumab and APAcCNF were only improved slightly compared to the corresponding DC treated in the presence of irrelevant $\mathrm{Ab}$ (Figure S2). These results suggested that the stimulation of IL-6 by APAcCNF in DC was only partially involved in the regulation of their differentiation and maturation capacity, so other mechanisms were probably more dominant.

\section{CNF impair DC capacity to stimulate proliferation and differentiation of Th I and ThI 7 cells}

To assess the functions of DC in contact with T cells, allogeneic purified $\mathrm{CD}^{+} \mathrm{T}$ cells were cocultivated with $\mathrm{DC}$ at 
different cell-to-cell ratios for 5 days. The proliferation of $\mathrm{T}$ cells was assessed by labeling of $\mathrm{T}$ cells with CFSE and monitoring the CFSE fluorescence dilution by flow cytometry after coculturing with DC (Figure $3 \mathrm{~A}$ and $\mathrm{B}$ ). It was found that mature CNF-DC possessed significantly lower capacity to stimulate T-cell proliferation compared to the corresponding control (LPS/IFN- $\gamma$-stimulated) DC. In that sense, APAcCNF-DC displayed the lowest allostimulatory capacity, irrespective of their additional stimulation with LPS/IFN- $\gamma$.

The Th polarization capacity of DC was analyzed by measuring the levels of IL-17, IFN- $\gamma$, and IL-4 in DC/T-cell culture supernatants (Figure 3C), or intracellularly in T cells (Figure 3D and E). No changes in IFN- $\gamma$ and IL-17 levels were detected in cocultures with non-stimulated DC differentiated with either of the CNF samples. LPS/IFN- $\gamma$ stimulated the capacity of the control DC to induce IFN- $\gamma$ and IL-17, but not IL-4, production in coculture with T cells, as expected. ${ }^{34,37}$ However, stimulated CNF-treated DC had significantly lower capacity to induce IL-17 and IFN- $\gamma$ production, compared to the corresponding control stimulated DC. These results correlated with a lower percentage of IL- $17^{+}$and IFN- $\gamma^{+}$within $\mathrm{CD}^{+}$and $\mathrm{CD} 4^{-} \mathrm{T}$ cells $(>98 \%$ of $\mathrm{CD}^{+}$cells $^{40}$ ) cultivated with stimulated CNF-treated DC (Figure 3D and E). Immature cCNF-DC and APAcCNF-DC induced the production of IL-4 in coculture (Figure 3C) and increased the percentage of IL-4 producing $\mathrm{CD} 4^{+} \mathrm{T}$ cells (data not shown). However, after the maturation with LPS/IFN- $\gamma$, only nCNF-DC and APAcCNF-DC induced significantly higher production of IL-4 and increased the percentage of $\mathrm{IL}-4^{+} \mathrm{CD} 4^{+} \mathrm{T}$ cells (Figure 3D and E). The equivalent concentrations of soluble APA had no significant effects on the Th polarization capacity of DC either, so this control was not used in further experiments. Since the differences between CNF samples with regard to DC phenotype and functions were more prominent after the LPS/IFN- $\gamma$-treatment, further experiments were carried out with LPS/IFN- $\gamma$-stimulated DC for the sake of simplicity and convenience.
A

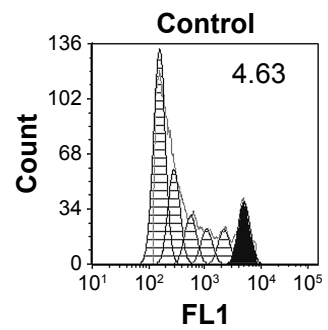

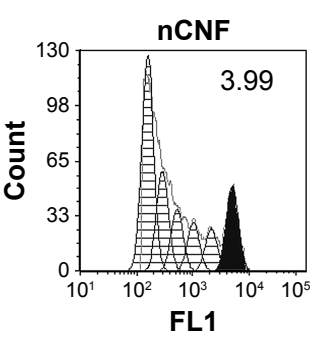
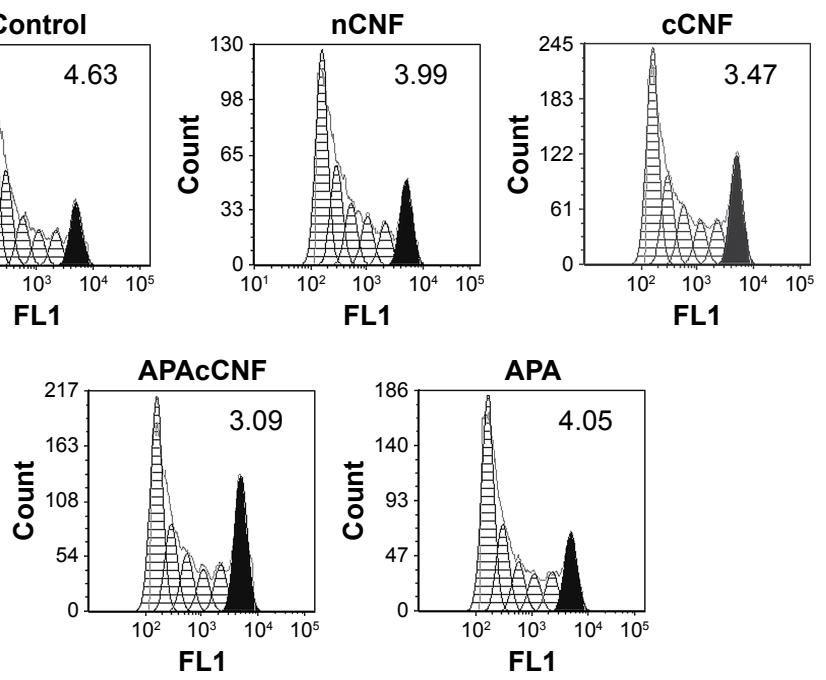

C

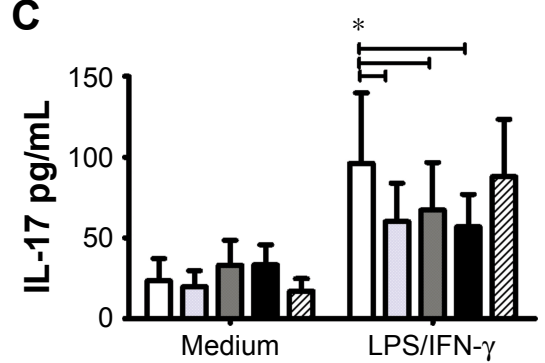

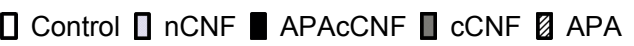

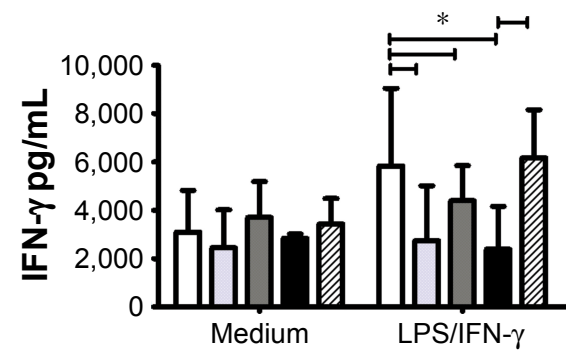

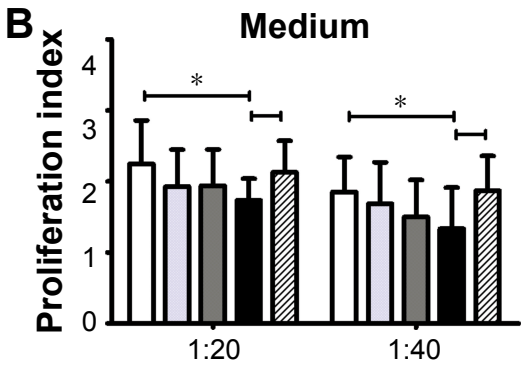
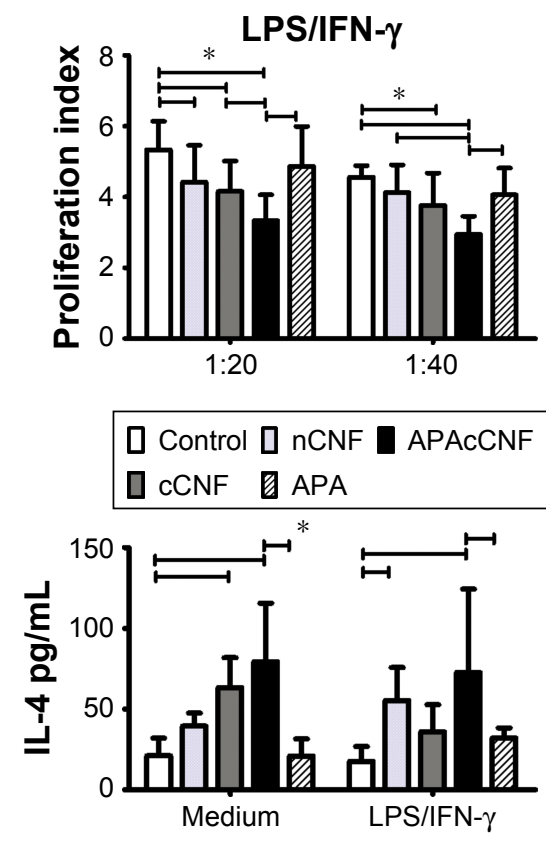

Figure 3 (Continued) 

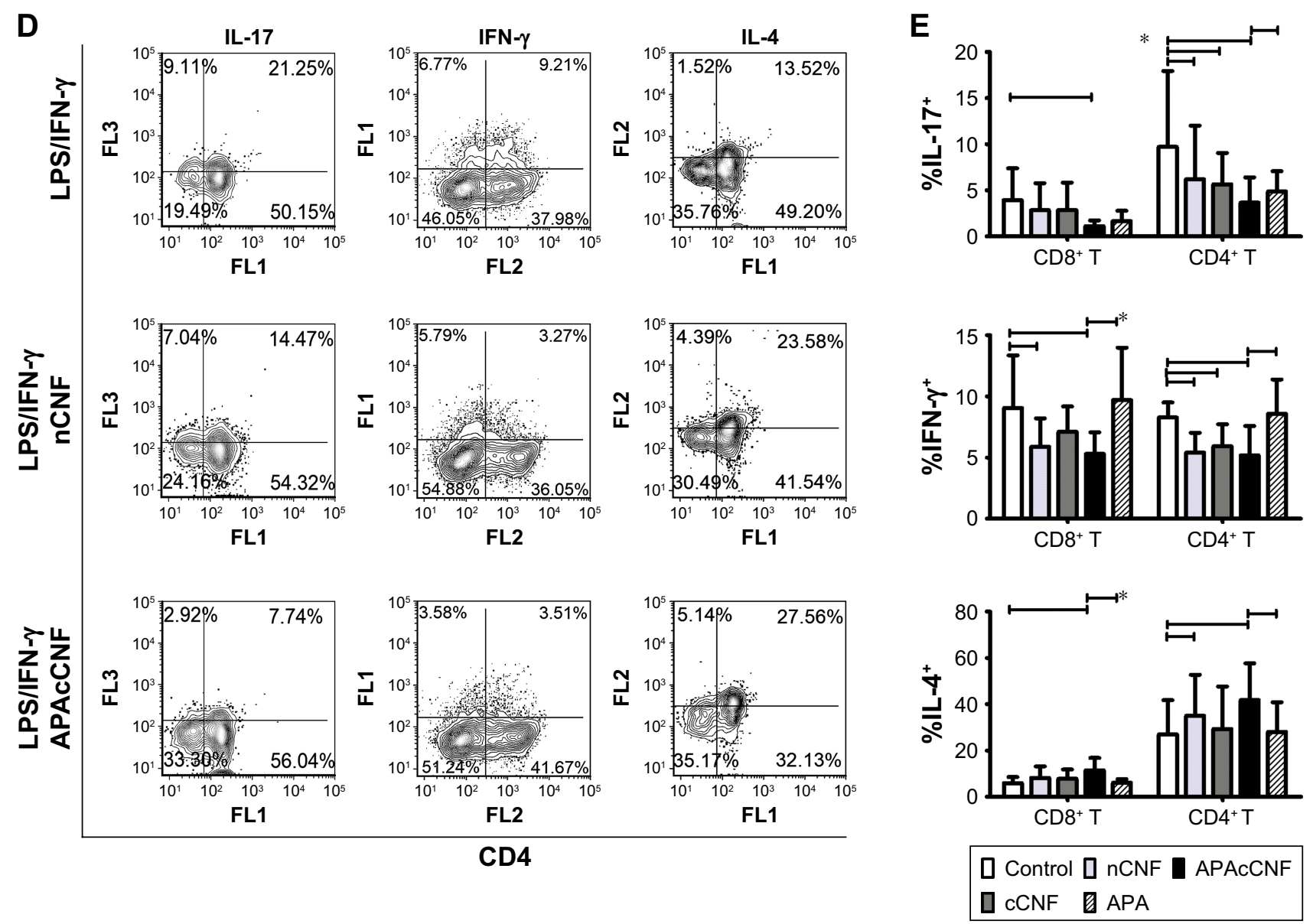

Figure 3 Effects of CNF samples on Th-polarization capacity of DC.

Notes: (A) A representative analysis of CFSE-labeled CD3 ${ }^{+}$T-cell proliferation in coculture with LPS/IFN- $\gamma$ stimulated DC at I:20 (DC:T cell) ratio (the number indicate proliferation index). (B) The summarized results on proliferation from four independent experiments are shown as mean proliferation index \pm SD. (C) The levels of cytokines in $\mathrm{DC} / \mathrm{CD}^{+} \mathrm{T}$-cell cocultures measured by specific ELISA are shown as mean $\mathrm{pg} / \mathrm{mL} \pm \mathrm{SD}$ from four independent experiments. (D) A representative analysis of intracellular cytokines' expression in $\mathrm{CD}^{+} \mathrm{T}$ cells from $\mathrm{DC} / \mathrm{T}$ cocultures. The data from three experiments with $\mathrm{T}$ cells which showed a marked expression of cytokines are shown. This was done since highly variable production of these cytokines by different T-cell donors was shown previously. ${ }^{45}$ (E) The summarized data from five independent experiments carried out with LPS/IFN- $\gamma$-stimulated DC are shown as mean \% of positive cells within CD4 ${ }^{+}$or $\mathrm{CD}^{-}{ }^{-}\left(\mathrm{CD} 8^{+}\right) \mathrm{T}$ cells $\pm \mathrm{SD}$. ${ }^{*} \mathrm{P}<0.05$ as indicated (RM ANOVA).

Abbreviations: APA, 3-aminopropylphosphoric acid; APAc, APA-functionalized; c, carboxylated; CFSE, carboxyfluorescein succinimidyl ester; CNF, cellulose nanofibrils; DC, dendritic cells; IFN, interferon; LPS, lipopolysaccharide; n, native; RM, repeated measures; Th, T helper cell.

\section{DC differentiated with nCNF, but not cCNF and APAcCNF, induce Tregs via IDO-I}

The impaired maturation and immunogenic functions of DC were shown to correlate with their increased potential to induce regulatory $\mathrm{T}$ cells. ${ }^{26}$ One of the key mechanisms by which human tolerogenic DC induce $\mathrm{CD} 4^{+} \mathrm{CD} 25^{\text {hi }}$ FoxP $3^{\text {hi }}$ Treg includes IDO-1-dependent mechanisms. ${ }^{26}$ Therefore, we first assessed intracellular expression of IDO-1 by flow cytometry and found that stimulated nCNF-DC expressed significantly higher levels of IDO-1 compared to the stimulated control DC (Figure 4A and B). As expected, nCNF-DC in coculture with $\mathrm{CD}^{+} \mathrm{T}$ cells induced significantly higher percentage of $C D 4^{+} \mathrm{CD} 25^{\text {hi }}$ FoxP $3^{\text {hi }}$ cells (Figure $4 \mathrm{C}$ and D).
In contrast, cCNF-DC and APAcCNF-DC did not upregulate IDO- 1 expression and did not induce $\mathrm{CD} 4^{+} \mathrm{CD} 25^{\text {hi }}$ FoxP $3^{\text {hi }}$ Treg in the coculture (Figure 4A-D).

In coculture supernatants, significantly higher levels of TGF- $\beta$ were detected in nCNF-DC/T-cell cocultures, whereas the increase of IL-10 was not significant compared to cocultures with the control DC (Figure 4E). Interestingly, APAcCNF-DC induced significantly higher production of IL-10 in cocultures, whereas TGF- $\beta$ levels increased insignificantly compared to the corresponding control cocultures. The levels of IL-10 and TGF- $\beta$ in cocultures with cCNF-DC were not increased significantly compared to the control cocultures (Figure 4E). To assess whether T cells cocultivated with CNF-treated DC display any suppressive potential, 
A
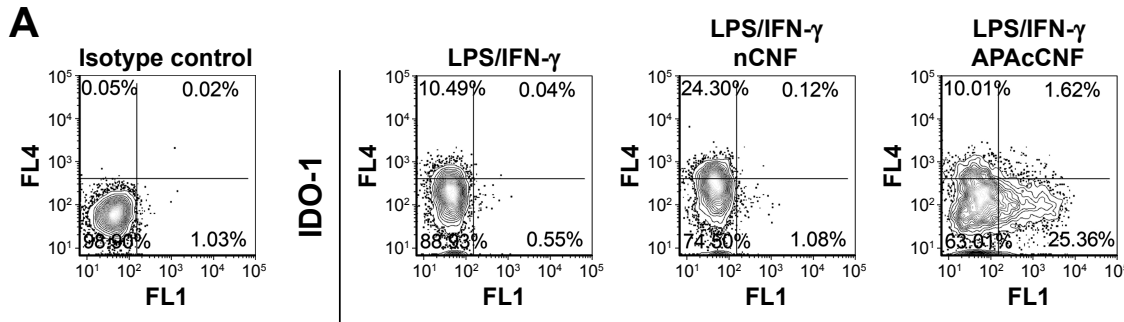

CD14

C

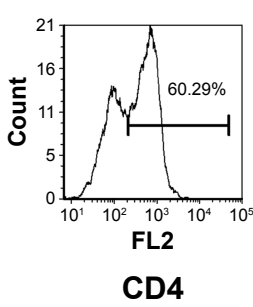

E

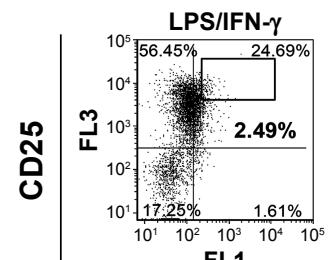

FL1

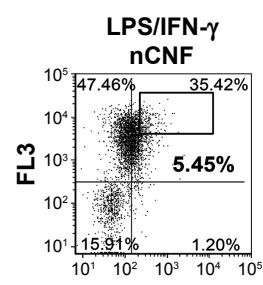

FL1

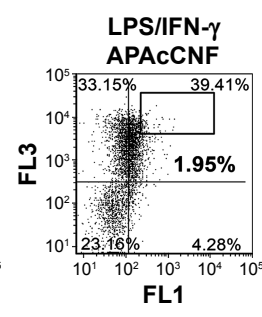

FL1
FoxP3
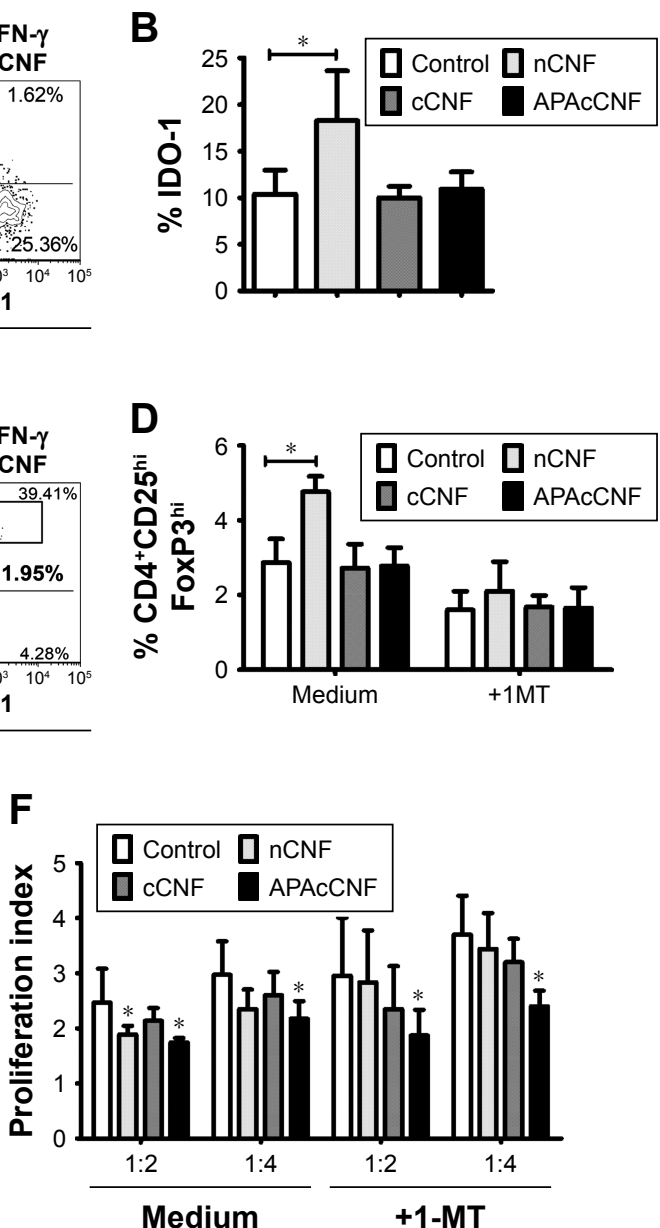

Figure 4 IDO-I-dependent mechanisms in tolerogenic effects of CNF-treated DC.

Notes: (A) A representative analysis of IDO-I expression in DC gated cells is shown and, (B) the summarized data from three independent experiments are shown as mean $\pm S D$. (C) A representative analysis of CD4 ${ }^{+} C D 25^{\text {hi FoxP3 }}{ }^{\text {hi }} \mathrm{T}$ cells after the cultures with $\mathrm{DC}$ is shown and, (D) the summarized data from four independent experiments are shown as mean $\% \pm$ SD. Representative data for CCNF- DC, omitted in A and C, were similar to those obtained with APAcCNF-treated DC. (E) The levels of cytokines in supernatants of DC/T cell cocultures are shown as mean $\mathrm{pg} / \mathrm{mL}$ of three independent experiments. (F) The proliferation of allogeneic responder CFSE-labeled $C D 3^{+} \mathrm{T}$ cells in the presence of $\mathrm{T}$ cells primed with $\mathrm{DC}$ from three independent experiments is shown as mean proliferation index $\pm \mathrm{SD}$. $* P<0.05$ compared to corresponding control, or as indicated (RM ANOVA).

Abbreviations: I-MT, one methyl tryptophan; APA, 3-aminopropylphosphoric acid; APAc, APA-functionalized; c, carboxylated; CNF, cellulose nanofibrils; DC, dendritic cells; FoxP, forkhead box protein; IDO, indolamine dioxygenase; IFN, interferon; LPS, lipopolysaccharide; n, native; RM, repeated measures; TGF, transforming growth factor.

they were cocultivated with CFSE-labeled allogeneic $\mathrm{CD}^{+}$ $\mathrm{T}$ cells in the presence of anti-CD3/anti-CD28 Ab stimulation (Figure 4F). The results showed that $\mathrm{T}$ cells primed with nCNF-DC and APAcCNF-DC suppressed significantly the proliferation of responder allogeneic $\mathrm{T}$ cells at 2:1 and 4:1 ratios ( $\mathrm{T}$ responder:T primed cell ratio), respectively. When the priming of $\mathrm{T}$ cells in coculture with $\mathrm{DC}$ was carried out in the presence of IDO-1 inhibitor 1-MT, T cells primed with nCNF-DC contained a significantly lower percentage of $\mathrm{CD} 4^{+} \mathrm{CD} 25^{\text {hi }} \mathrm{FoxP}^{\text {hi }}$ cells (Figure 4D), and the primed $\mathrm{T}$ cells displayed no significant suppression of allogenic $\mathrm{T}$ cell proliferation (Figure 4F). In contrast, $\mathrm{T}$ cells primed with APAcCNF-DC displayed the suppressive capacity even if the priming was carried out in the presence of 1-MT.
The suppressive effects of $\mathrm{T}$ cells primed with cCNF-DC were detected, but the differences were not significant compared to the control $\mathrm{T}$ cells. These results suggested that, unlike nCNF-DC, APAcCNF-DC induce suppressive T cells other than $\mathrm{CD} 44^{+} \mathrm{CD} 25^{\text {hi }}$ FoxP $3{ }^{\text {hi }}$ Treg, via IDO-1-independent mechanisms.

\section{APACCNF-DC induce predominantly suppressor $C D 8^{+} T$ cells via ILT-3 and ILT-4}

Additional molecules, such as ILT-4 and ILT-3, were shown to be involved in DC-mediated tolerogenic effects and induction of $\mathrm{CD}^{+} \mathrm{IL}-10^{+41}$ and $\mathrm{CD} 8^{+} \mathrm{IL}-10^{+42}$ regulatory T-cell populations, respectively, some of which use 
IFN- $\gamma$ for their suppressor activity. ${ }^{43,44}$ The assessment of ILT-3 and ILT-4 expression on stimulated DC showed that APAcCNF-DC, unlike nCNF-DC, displayed significantly higher expression of both markers compared to the control stimulated DC (Figure 5A and B). No significant upregulation of ILT-3 and ILT-4 on cCNF-DC was detected. Next, we assessed which T-cell population increased IL-10 expression after the priming with DC, and how this correlated with their IFN- $\gamma$ expression (Figure 5C and D). Flow cytometry analysis showed that cCNF-DC upregulated IL-10 expression by $\mathrm{CD}^{+} \mathrm{T}$ cells significantly. APAcCNF-DC upregulated IL-10 expression by both $\mathrm{CD}^{+}$and $\mathrm{CD}^{+} \mathrm{T}$ cells (within both IFN $-\gamma^{+}$and IFN $-\gamma$ population), whereas the upregulation of IL- $10^{+} \mathrm{T}$ cells cocultivated with nCNF-DC was not significant statistically. The highest expression of IL-10 was detected in the $\mathrm{CD}^{+} \mathrm{IFN}-\gamma^{+} \mathrm{T}$-cell population after the priming with APAcCNF-DC (Figure 5C and D).

Therefore, we explored in more detail the phenotype and functions of the $\mathrm{CD} 8^{+} \mathrm{T}$ cells primed with APAcCNF-DC. $\mathrm{CD}^{+} \mathrm{T}$ cells were MACS-purified and then cocultivated with APAcCNF-DC for 6 days, followed by their flow cytometry analysis according to the markers proposed for suppressor $\mathrm{CD}^{+} \mathrm{T}$ cells. ${ }^{45}$ It was found that, even in the absence of $\mathrm{CD} 4^{+} \mathrm{T}$ cells, APAcCNF-DC induced significantly higher percentage of IL- $10^{+}$cells within the $\mathrm{CD} 8^{+} \mathrm{CD} 25^{+}$population (Figure $6 \mathrm{~A}$ and $\mathrm{B}$ ), whereas $\mathrm{CD} 8^{+} \mathrm{CD} 25^{-} \mathrm{T}$ cells did not express significant levels of IL-10 (data not shown). The increased IL-10 expression was detected in both IFN $-\gamma^{+}$and IFN $-\gamma$ CD $8^{+} \mathrm{CD} 25^{+}$
A
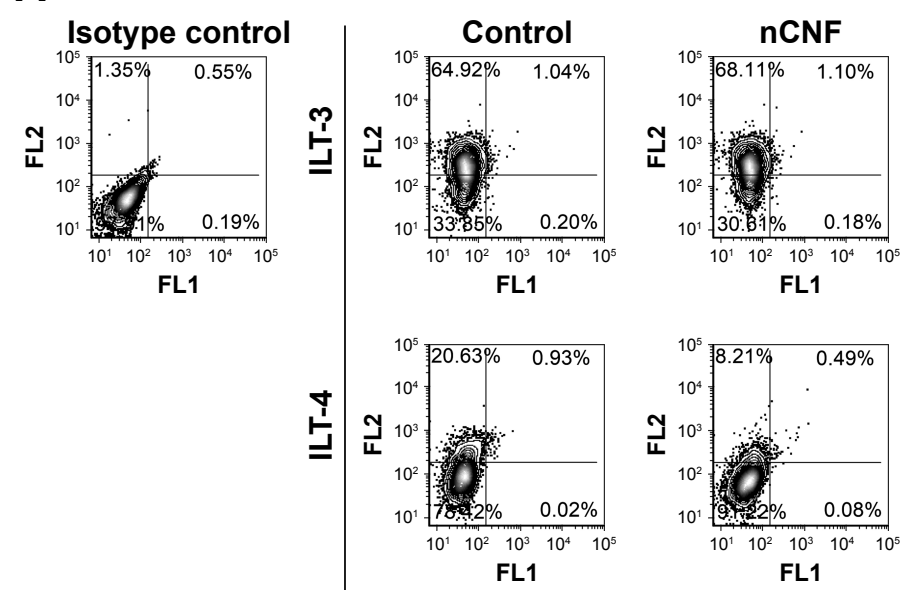

FL1

CD14
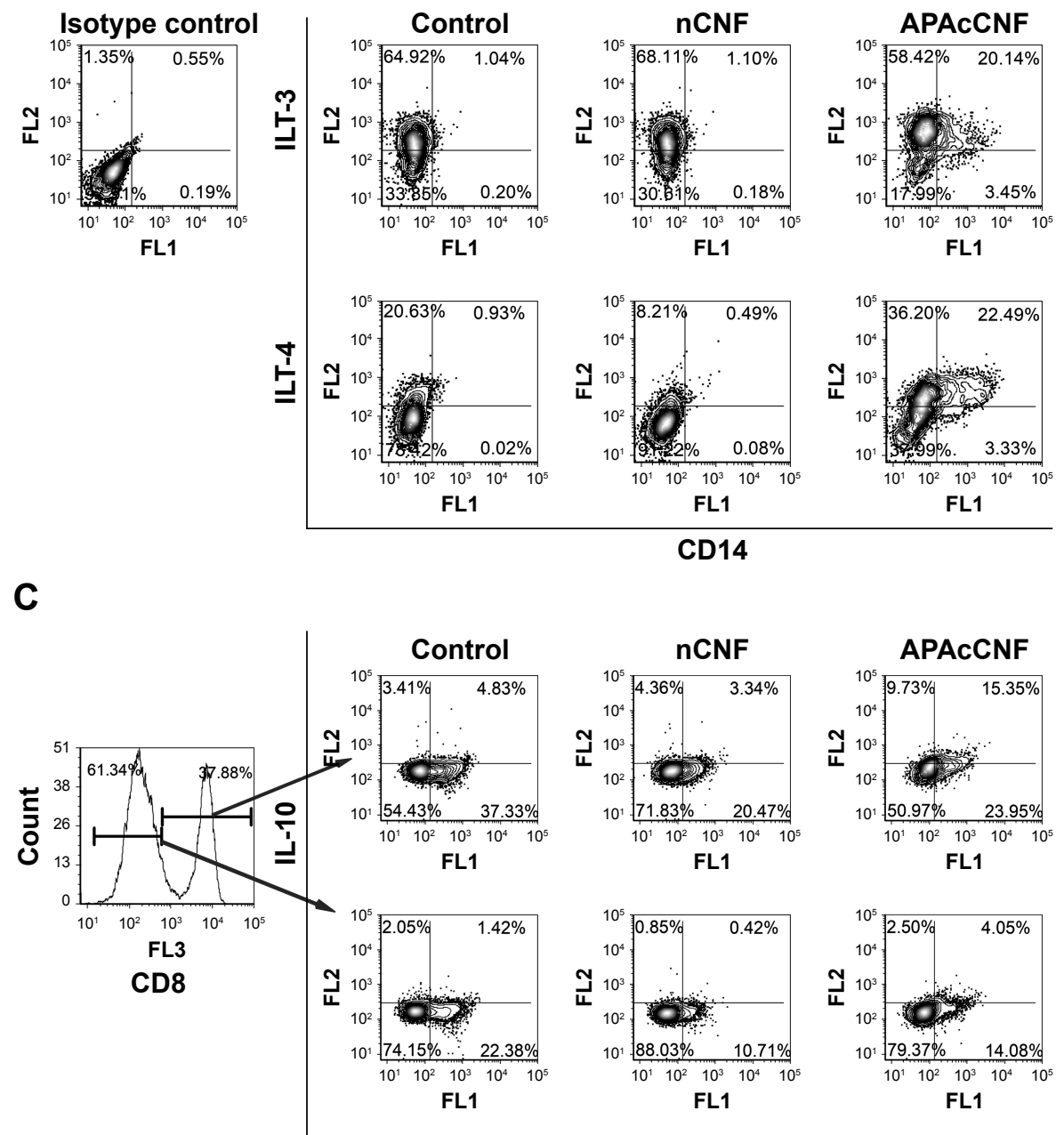

IFN- $\gamma$
B

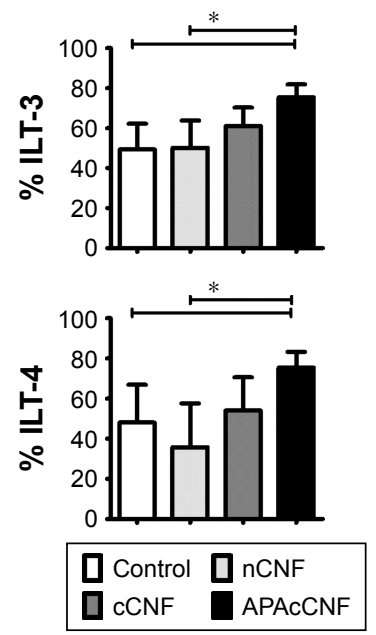

D
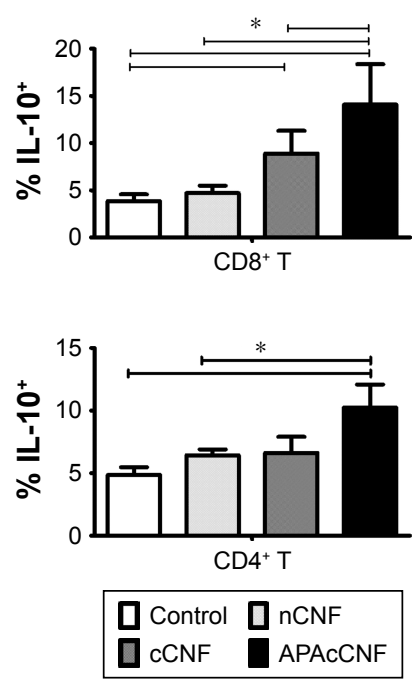

Figure 5 ILT3-dependent mechanisms of APACCNF-DC.

Notes: (A) A representative analysis of ILT3 and ILT4 in CNF-treated DC and, (B) the summarized data from four independent experiments are shown as mean \pm SD. (C) The analysis of IL- 10 and IFN- $\gamma$ expression in T cells primed with DC from one experiment is shown (gating markers from CD8 ${ }^{+}$and $\mathrm{CD}^{-}$[CD4 $^{+}$] $\mathrm{T}_{\text {cell }}$ populations are indicated by arrows), and (D) the summarized data on \% of total IL- $10^{+}$cells within $C D 8^{+}$and $C D 4^{+} T$ cells is presented as mean \pm SD of four independent experiments. $* P<0.05$ as indicated (RM ANOVA).

Abbreviations: APA, 3-aminopropylphosphoric acid; APAc, APA-functionalized; CNF, cellulose nanofibrils; DC, dendritic cells; IFN, interferon; ILT, immunoglobulin-like transcript; LPS, lipopolysaccharide; RM, repeated measures. 

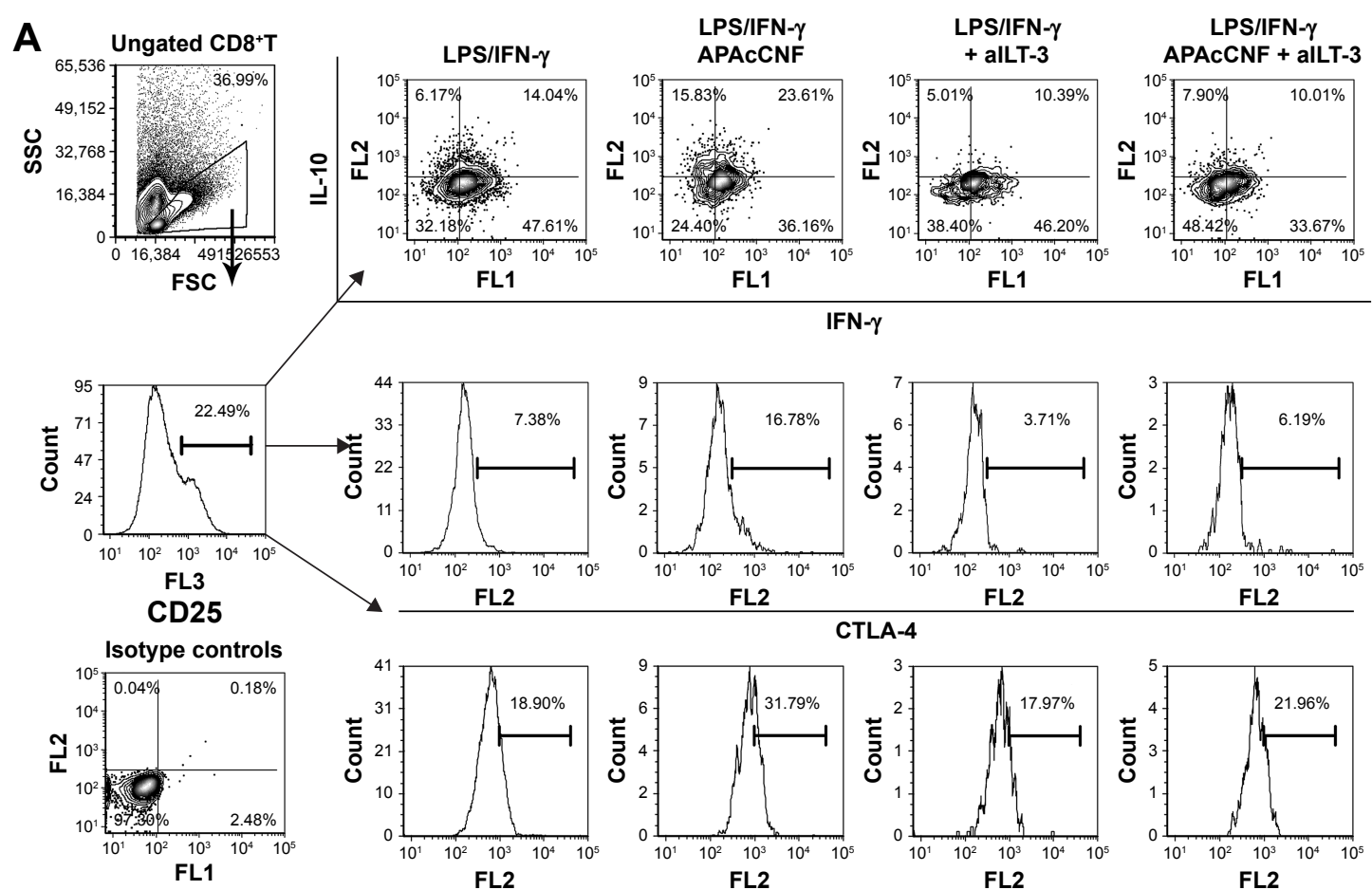

IFN- $\gamma$
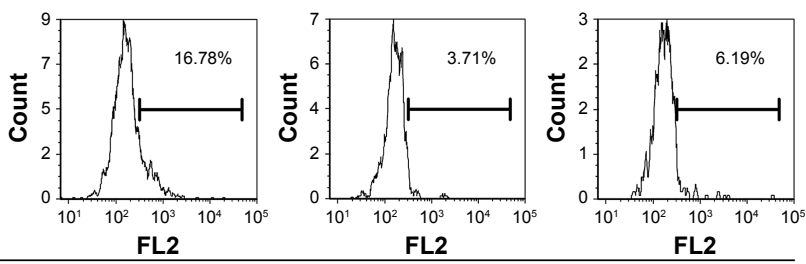

CTLA-4

B
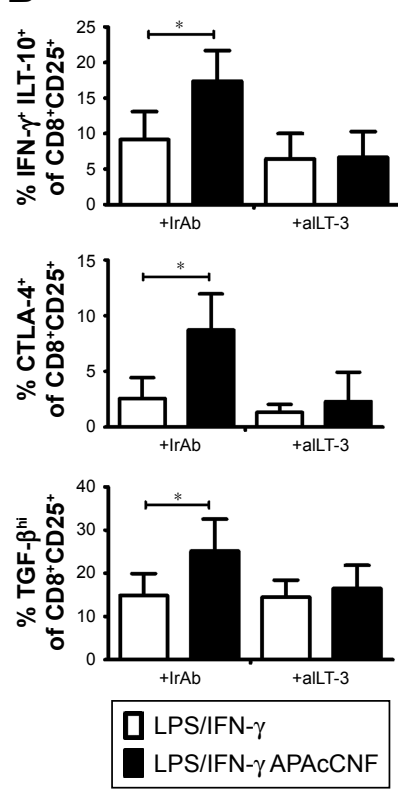
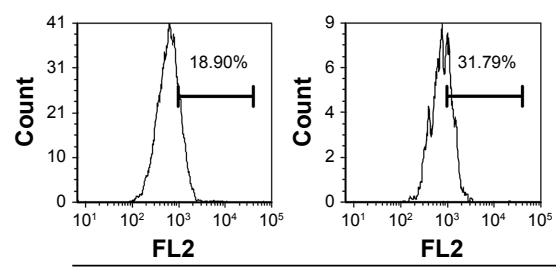

C $\overline{\mathbf{n}}$

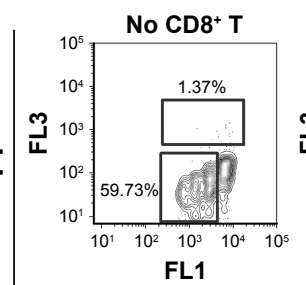

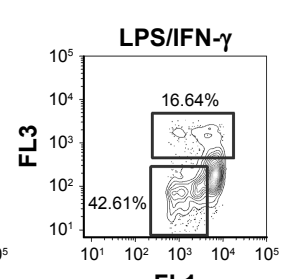

FL1
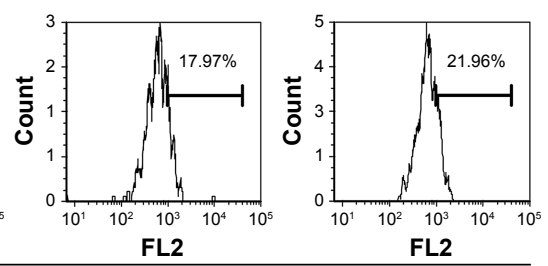

FL2

FL2

TGF- $\beta$

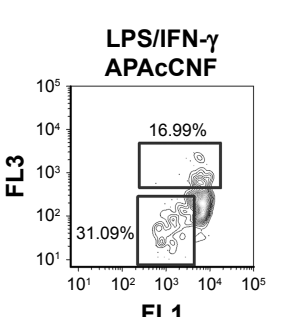

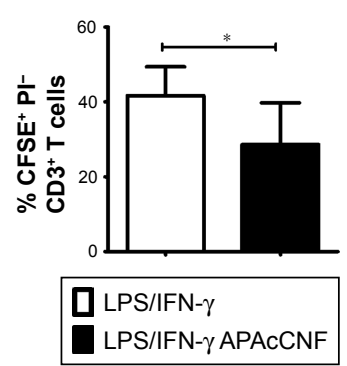

D

CFSE PS/IFN- $\gamma$ APACCNF

D

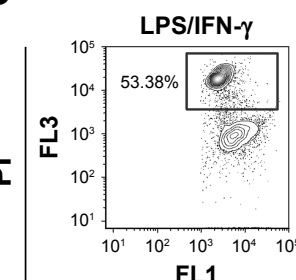

FL1
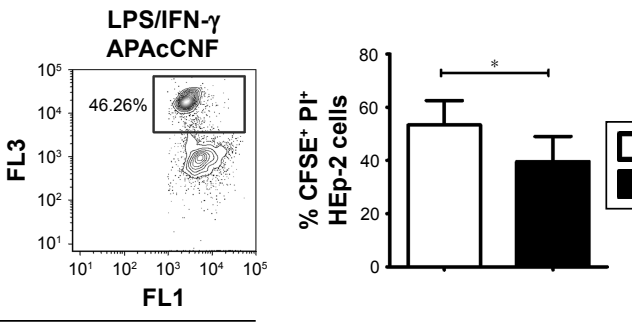

LPS/IFN- $\gamma$

LPS/IFN- $\gamma$ APACCNF

CFSE

Figure 6 Phenotype of regulatory $C D 8^{+} \mathrm{CD} 25^{+} \mathrm{T}$ cells induced by $\mathrm{DC}$.

Notes: (A) MACS purification and gating strategy of CD8 ${ }^{+}$T cells cocultivated with DC in the presence or absence of blocking anti-ILT-3 Ab (see also Figure S3 for the experiments with the blocking anti-ILT-4 Ab), for the analysis of IFN- $\gamma$, IL-10, CTLA-4, and TGF- $\beta$ expression within CD25+CD8 ${ }^{+}$population. (B) The summarized data from four different experiments are shown as mean \pm SD. $* P<0.05$ as indicated (RM ANOVA). (C) The proliferation (CFSE) and cell-death (PI) analysis of the allogeneic CFSElabeled $\mathrm{CD}^{+} \mathrm{T}$ cells cocultivated with $\mathrm{DC}$-primed $\mathrm{CD} 8^{+} \mathrm{T}$ cells. A representative analysis and the summarized data from four independent experiments are shown as mean $\%$ of proliferated responders \pm SD. (D) Cytotoxic activity of DC-primed CD8 ${ }^{+}$T cells toward CFSE-labeled tumor HEp-2 cells. Representative data on gated CFSE + HEp-2 cells are shown, and the summarized data from three different experiments are shown as mean $\pm S D$. $* P<0.05$ compared to control (paired $t$-test).

Abbreviations: Ab, antibody; alLT-3, blocking anti-ILT-3 antibody; APA, 3-aminopropylphosphoric acid; APAc, APA-functionalized; CFSE, carboxyfluorescein succinimidyl ester; CNF, cellulose nanofibrils; CTLA, cytotoxic T-lymphocyte-associated protein; DC, dendritic cells; IFN, interferon; +IrAb, irrelevant antibody; ILT, immunoglobulin-like transcript; LPS, lipopolysaccharide; MACS, magnetic-activated cell sorting; PBMC, peripheral blood mononuclear cells; PI, propidium iodide; RM, repeated measures; TGF, transforming growth factor.

$\mathrm{T}$ cells, but a higher percentage of $\mathrm{CD} 8^{+} \mathrm{CD} 25^{+} \mathrm{IFN}-\gamma^{+} \mathrm{T}$ cells expressed IL-10. Additionally, CD $8{ }^{+} \mathrm{CD} 25^{+} \mathrm{T}$ cells expressed higher levels of CTLA-4 and TGF- $\beta$ (Figure 6A and B).
ILT-3 was described as a master inducer of regulatory $\mathrm{CD} 8^{+} \mathrm{T}$ cells, ${ }^{42}$ so we tested whether the blockage of ILT-3 could alleviate the effect of APAcCNF-DC on $\mathrm{CD} 8^{+} \mathrm{T}$ cells. 
In the presence of anti-ILT-3 Ab, no increase in IL-10, TGF- $\beta$, and CTLA-4 expression was observed in the $\mathrm{CD} 8^{+} \mathrm{CD} 25^{+}$ populations in comparison to the corresponding $\mathrm{CD} 8^{+} \mathrm{CD} 25^{+}$ $\mathrm{T}$ cells cocultivated with control DC in the presence of isotype control Ab (Figure 6A and B). Similar phenomenon was observed when ILT-4 was blocked with APAcCNF-DC (Figure S3) during the priming of purified $\mathrm{CD}^{+} \mathrm{T}$ cells. In addition to suppressive phenotype, $\mathrm{CD} 8^{+} \mathrm{T}$ cells primed with APAcCNF-DC suppressed the proliferation of CFSElabeled allogeneic $\mathrm{CD}^{+} \mathrm{T}$ cells in the presence of CD3/CD28 stimulus, and this was not due to their increased cytotoxicity (Figure 6C). Moreover, CD ${ }^{+} \mathrm{T}$ cells primed with syngeneic APAcCNF-DC pulsed with HEp-2 lysate, displayed a lower cytotoxicity toward HEp- 2 cell line, compared to $\mathrm{CD} 8^{+} \mathrm{T}$ cells primed with the control DC that were not differentiated in the presence of APAcCNF (Figure 6D). These data suggested that APAcCNF-DC induces predominantly suppressive CD8 ${ }^{+}$ T-cell populations in ILT-3- and ILT-4-dependent manner.

\section{Discussion}

While good biocompatibility of CNF in vitro and in vivo was described previously, ${ }^{2,9}$ their immunomodulatory actions were not investigated sufficiently, even though that could have explained some of the beneficial clinical effects observed. ${ }^{5}$ Previous findings suggested that different cellulose-based nanomaterials could have anti-inflammatory effects in vivo ${ }^{16}$ and in vitro, ${ }^{9}$ but more detailed immunological mechanisms remained largely unknown. Our recent findings suggested that $\mathrm{nCNF}$ can induce beneficial tolerogenic response in human immune cells, ${ }^{9}$ including DC. ${ }^{31}$ Here, we showed for the first time that such an effect could even be potentiated by phosphonation of CNF, making them suitable for further development as bone tissue scaffolds. ${ }^{7}$ More interestingly, APA-functionalized CNF induced stronger tolerogenic properties in DC by activating mechanisms that mediate induction of different Treg populations, thus providing a good platform for a well-controlled DC-mediated induction of tolerogenic immune response.

All tested CNF altered the differentiation of DC from monocytes, as indicated by the impaired upregulation of CD1a and CD209 during differentiation. CD1a ${ }^{+}$DC were shown to produce more IL-12 and induce Th1 polarization, ${ }^{46}$ whereas CD1a- DC displayed a weaker maturation potential and a higher capacity to produce IL-10 and regulatory T cells. ${ }^{47}$ Such an effect of nCNF from a different source, ${ }^{31}$ as well as other nanomaterials ${ }^{34,36}$ and cultivation procedures, ${ }^{24,48}$ was described previously by our group. Therefore, the ratio between $\mathrm{CD} \mathrm{a}^{+}$and CD1a- DC might be a good indicator of DC tolerogenicity. However, it is unclear whether an increased expression of CD14, alongside low CD1a expression, is an indication of shifted differentiation of monocytes toward macrophage-like cells. Chomarat et al ${ }^{39}$ showed that high concentrations of IL-6 (up to $150 \mathrm{ng} / \mathrm{mL}$ ) shift monocytes' differentiation toward macrophage-like cells. However, APAcCNF induced much lower IL-6 production by DC (up to $20 \mathrm{ng} / \mathrm{mL}$ ), and the blockade of IL-6R only partially restored APAcCNF-mediated inhibition of DC differentiation, suggesting that IL-6 was not fully responsible for the increased CD14 expression on DC. Alternatively, both expression of CD14 and IL-6 could indicate DC tolerogenic properties. In line with this, Gregori et $\mathrm{al}^{49}$ described a population of tolerogenic IL-10-producing DC which displayed $\mathrm{CD} 1 \mathrm{a}^{-} \mathrm{CD} 14^{+}$phenotype, expressed high levels of IL-6, IL-10, and ILT-4, as well as low levels of IL-12, which is in line with the phenotype of APAcCNF-DC. The fact that similar cells can be differentiated from monocytes in vitro in the presence of IL- $10^{49}$ suggests that the autocrine production of IL-10 by APAcCNF-DC could be a major trigger for their tolerogenic phenotype and functions.

Functionally, APAcCNF-DC displayed the weakest capacity to express co-stimulatory molecules (CD86 and CD40) and HLA-DR. Additionally, a higher capacity of APAcCNF-DC to produce IL-10 and TGF- $\beta$, with known anti-proliferative effects, ${ }^{50,51}$ could explain their weakest allostimulatory capacity. Both of these cytokines were shown to suppress the production of IL-12 and IL-23, ${ }^{52}$ which are involved in the induction and maintenance of Th1 and Th17 cells, respectively. ${ }^{53}$ Besides, an increased expression of IL-27 by APAcCNF-DC probably contributed to their lowest capacity to induce IL-17 ${ }^{+} \mathrm{T}$ cells, as IL-27 directly inhibit Th17 development and functions. ${ }^{54}$ Downregulation of Th1 response can be a default pathway for development of Th2 response, but other mechanisms such as CD209-dependent upregulation of IL-10 and Notch ligands ${ }^{55}$ have been proposed as well. Taken together, all CNF-treated DC displayed a diminished Th1/Th17 and augmented Th2 polarizing capacity of DC, even in a strong Th1/Th17-inducing microenvironment, such as LPS/IFN- $\gamma \cdot{ }^{37}$ This could be quite beneficial for controlling different Th1- and Th17-mediated immunopathologies. ${ }^{53}$ In this sense, APAcCNF-DC exhibited the strongest effects, followed by nCNF and cCNF, respectively. The differences between CNF effects on Th polarization capacity of DC could be explained by the different cytokine profiles they induced in DC, and also by the different capacity of those $\mathrm{DC}$ to induce regulatory $\mathrm{T}$-cell populations.

It was previously shown that nCNF-DC induced CD $4{ }^{+} \mathrm{CD} 25^{\text {hi }}$ FoxP $3{ }^{\text {hi }}$ Treg, which exhibit suppressive functions, unlike activated $\mathrm{CD} 25^{+} \mathrm{FoxP} 3^{+}$Th cells. ${ }^{56} \mathrm{We}$ 
showed previously that the induced $\mathrm{CD} 4^{+} \mathrm{CD} 25^{\text {hi }}$ FoxP $3{ }^{\text {hi }}$ Treg express more CD39, TGF- $\beta$, and IL-10, which contribute significantly to the suppressive functions of Tregs. ${ }^{31,57}$ IDO-1 expression by tolerogenic DC was shown to be important for the induction of $\mathrm{CD} 4^{+} \mathrm{CD} 25^{\text {hiF }}$ FoxP $3^{\text {hi }}{ }^{26}$ which seems true for nCNF-induced tolerogenic DC as well. Previously, we showed that a higher dose of $\mathrm{nCNF}(500 \mu \mathrm{g} / \mathrm{mL})$ upregulated both ILT-4 and IDO-1, but downregulated ILT-3 expression by DC. ${ }^{31}$ According to the finding that ILT-3 is dispensable for the induction of $\mathrm{CD} 4{ }^{+} \mathrm{CD} 25^{\text {hi }} \mathrm{FoxP} 3{ }^{\text {hi }}$ Treg, ${ }^{58}$ but not CD ${ }^{+}$ regulatory $\mathrm{T}$ cells,${ }^{42}$ it is possible that $\mathrm{DC}$ treated with lower doses of nCNF induce predominantly $\mathrm{CD}^{+}$Tregs without affecting the $\mathrm{CD}^{+} \mathrm{T}$-cell compartment.

In contrast to $\mathrm{nCNF}$, APAcCNF-DC induced regulatory IL-10-producing $\mathrm{CD}^{+}$, and particularly, $\mathrm{CD}^{+} \mathrm{T}$-cell populations. $\mathrm{CD}^{+} \mathrm{IL}^{+} 0^{+} \mathrm{T}$ cells were recently interpreted as a heterogenous T-cell population with suppressive functions due to IL-10 production. ${ }^{41}$ Although described with different phenotype due to lack of specific markers, $\mathrm{CD}^{+}$ $\mathrm{T}$ cells expressing high levels of IL-10, moderate levels of IFN- $\gamma$, and low levels of IL-4 are often referred to as $\operatorname{Tr} 1 /$ Tr1-like cells. ${ }^{41,59}$ Gregori et $\mathrm{al}^{49}$ showed that tolerogenic CD1a-CD14 ${ }^{+}$IL-10-producing DC induce $\operatorname{Tr} 1$ cells via ILT-4, although it remained unclear what effects DC-10 have on $\mathrm{CD}^{+}$T cells. IL-10, IL-6, IL-27, and ILT-4 were shown to be important inducers of $\operatorname{Tr} 1 / \operatorname{Tr} 1$-like cells, ${ }^{60,61}$ all of which could explain the effects of APAcCNF-DC in the induction of IL-10-producing $\mathrm{CD} 4^{+} \mathrm{IFN}-\gamma^{+} \mathrm{T}$ cells. An increased expression of IL-10 in CD4 $4^{+}$IFN- $\gamma$ T cells after the priming with APAcCNF-DC could also be a result of expanded Th2 cells, as they were also shown to produce IL-10, but not IFN- $\gamma .{ }^{59}$

In addition to IL-10-producing CD4 ${ }^{+} \mathrm{T}$ cells, DC differentiated in the presence of $\mathrm{cCNF}$, and APAcCNF particularly, induced a higher expansion of regulatory IL-10-producing $\mathrm{CD}^{+} \mathrm{T}$ cells, which correlated with their high ILT-3 and ILT-4 expression. ILT-3 was described as a key inducer of suppressor $\mathrm{CD}^{+} \mathrm{T}$ cells, which was confirmed in this study as well. However, although both regulatory $\mathrm{CD} 4^{+}$and $\mathrm{CD} 8^{+}$ $\mathrm{T}$ cells were shown previously to express ILT-4 ligand, HLA-G, ${ }^{62}$ it was not clearly defined whether ILT-4 also plays an important role in the induction of regulatory $\mathrm{CD} 8^{+}$ T cells. To our knowledge, this is the first study to show that both ILT-3 and ILT-4 contribute to the expansion of human regulatory $\mathrm{CD}^{+} \mathrm{T}$ cells by tolerogenic DC. Different regulatory $\mathrm{CD}^{+} \mathrm{T}$-cell populations were described in rodents, and some human counterparts have been proposed, ${ }^{63,64}$ but not clearly defined. ${ }^{65}$ Functional IL-2 receptor (CD25/CD122) seems to be critical for the expansion of $\mathrm{CD}^{+}$Treg both in humans and mice, ${ }^{64,65}$ which could explain why the upregulation of IL-10, CTLA-4, and TGF- $\beta$ was exclusive for $\mathrm{CD}_{25}$, but not for $\mathrm{CD} 25^{-} \mathrm{CD} 8^{+} \mathrm{T}$ cells. It is not yet clear how FoxP3 expression in human $\mathrm{CD}^{+} \mathrm{T}$ cells correlates with their regulatory phenotype and functions, since FoxP3 is a marker of activated $\mathrm{T}$ cells as well. ${ }^{66}$ Zheng et $\mathrm{al}^{67}$ showed that human alloantigen specific $\mathrm{CD}^{+} \mathrm{T}$ cells display memory-like phenotype and mediate suppression via IL-10, CTLA-4, and TGF- $\beta$. Although the authors showed that IFN- $\gamma$ is expressed highly by $\mathrm{CD} 8^{+}$Treg population, ${ }^{67}$ its presence was not clarified. IFN- $\gamma$ is a potent inducer of IDO- $1,{ }^{26}$ but IDO-1 independent suppressive effects of IFN- $\gamma$ were demonstrated as well. ${ }^{44,68}$ Therefore, it is possible that IFN- $\gamma$ expression by human regulatory $\mathrm{CD}^{+} \mathrm{T}$ cells is both a marker and a suppressive mediator of human regulatory $\mathrm{CD} 8^{+}$ $\mathrm{T}$ cells. However, additional phenotypical characterization of $\mathrm{CD}^{+} \mathrm{CD}^{2} 5^{+} \mathrm{IL}-10^{+} \mathrm{T}$ cells should be available, to clarify whether more than one $\mathrm{CD} 8^{+} \mathrm{IL}-10^{+}$regulatory subpopulation was induced by APAcCNF-DC. The somewhat higher suppressive capacity of T cells induced by APAcCNF-DC, compared to those induced by nCNF-DC (Figure 4F), could be explained by the fact that APAcCNF-DC induced both $\mathrm{CD}^{+}$and $\mathrm{CD}^{+}{ }^{+} \mathrm{IL}-10$-producing $\mathrm{T}$ cells, but also due to the potentially higher suppressive capacity of $\mathrm{CD}^{+}$regulatory $\mathrm{T}$ cells compared to $\mathrm{CD} 4^{+} \mathrm{CD} 25^{\text {hi }} \mathrm{FoxP} 3^{\text {hi }}$ cells. In line with this, it was shown that mice regulatory $\mathrm{CD} 8^{+}$Tregs are more potent in the suppression of allograft rejection than conventional CD ${ }^{+} \mathrm{CD} 25^{+}$Tregs. ${ }^{30,64}$ Unlike previous studies which showed an increased cytotoxicity of human regulatory $\mathrm{CD}^{+}{ }^{+} \mathrm{CD} 103^{+} \mathrm{T}$ cells, ${ }^{69} \mathrm{CD}^{+} \mathrm{T}$ cells induced by HEp 2 lysatepulsed APAcCNF-DC displayed a diminished cytotoxicity potential toward tumor HEp2 cell line. Although cytotoxicity of the induced allogeneic $\mathrm{CD}^{+} \mathrm{T}$ cells toward HEp2 cells was still high, a diminished cytotoxicity potential of induced $\mathrm{CD}^{+} \mathrm{T}$ cells could be a problem if the organism ought to fight infections and tumor. In that sense, adverse effects, such as loss of immune surveillance of tumors and a weaker control of infections, were described in both autoimmunity and transplantation immunotherapies. ${ }^{70}$ Therefore, besides the strength of the induced suppressive mechanisms, potentially adverse effects should be considered when designing a therapy for autoimmunity and transplantation. Developing new tools which can control the induction of regulatory mechanisms more precisely, such as those based on CNF, could be a good starting point. Our pilot experiment in vivo, in a rat model of experimental autoimmune encephalomyelitis, a model of multiple sclerosis, ${ }^{71}$ suggested that the rat bone marrow-derived DC display a tolerogenic phenotype upon differentiation with APAcCNF, and when applied 
prophylactically, delayed the onset, enhanced recovery, and reduced the overall clinical signs of the disease. These studies, and additional ones on different models of autoimmunity and transplantation, could provide important clues to which tolerogenic mechanisms should be targeted in the development of a specific immunotherapy.

The precise mechanisms by which CNF samples induced different tolerogenic effects on DC remain unclear. It is possible that CNF size and composition could have induced different effects in DC leading to their divergent tolerogenic response. An increased expression of actin filaments at the place of contact with CNF, according to their role in internalization, ${ }^{72}$ suggests that $\mathrm{CNF}$ provide enough signals for DC to internalize them. Signaling through C-type lectins, such as CD209, was shown to regulate the activity of small GTPases RhoA, Rac1, and Cdc42, which are the central regulators of actin dynamics during DC internalization and functions. ${ }^{73} \mathrm{CNF}$ contains different branching glycans ${ }^{31}$ able to ligate CD209. ${ }^{74}$ CD209 expression was indeed increased at the place of contact with nCNF and cCNF, but not with APAcCNF, which downregulated the expression of this molecule by DC significantly. In line with this, it was shown that the ligation of CD209 during DC differentiation downregulates CD209 expression and induces tolerogenic DC with low CD1a and high CD14 expression. ${ }^{75}$ Upon stimulation with LPS, those DC displayed a reduced Th1 polarizing capacity and increased expression of ILT-3 and IL-10, ${ }^{75}$ but it remained unknown how these correlate with DC capacity to induce Treg. Actin cytoskeleton alone can act as a cell's mechanosensitive receptor. ${ }^{76}$ Previous data demonstrated that DC which adhered to the multi-walled carbon nanotubes-based scaffolds during differentiation displayed an impaired LPS-induced maturation, allostimulatory capacity, and the production of IL-12. ${ }^{18}$ In this sense, it is possible that different tolerogenic effects of nCNF were due to their larger size compared to cCNF and APAcCNF. Although similarly sized, APAcCNF displayed stronger tolerogenic effects on DC than cCNF, possibly due to increased local concentrations of APA attached to CNF. APA was shown to activate metabotropic GABA-B receptors partially, ${ }^{77}$ which are involved in migration of inflammatory cells to the skin, pointing to its anti-inflammatory effects. ${ }^{78}$ However, the role of GABA-B receptors in DC biology is still unknown.

\section{Conclusion}

Here, we showed for the first time that CNF induction of DC-mediated anti-inflammatory effects can be potentiated by functionalization of CNF with APA. Additionally, the functionalization of CNF shifted the tolerogenic properties of
$\mathrm{DC}$, from those inducing predominantly $\mathrm{CD} 4^{+} \mathrm{CD} 25^{\text {hi }} \mathrm{FoxP} 3^{\text {hi }}$ Treg toward those inducing potentially more suppressive regulatory $\mathrm{CD}^{+}{ }^{+} \mathrm{CD} 25^{+} \mathrm{IL} 10^{+} \mathrm{T}$ cells. Different tolerogenic effects were mediated by induction of different regulatory molecules involved in DC tolerogenic activity, including IDO-1, ILT-3, and ILT-4. These results provide novel insights into immunomodulatory mechanisms of CNF and indicate their potential usefulness not only as well-tolerated scaffolds in tissue engineering, but also in designing a new platform for a controlled DC-mediated induction of tolerogenic immune response.

\section{Acknowledgments}

The authors are grateful to Dr Aleksandar Marinković, Faculty of Technology and Metallurgy, University of Belgrade, for performing the phosphate measurements on CNF samples. The work was supported financially by the Ministry of Education, Science and Technological Development of the Republic of Serbia (projects 175102, 173050), local grant of MMA (MFVMA/09/16-18), and the Slovenian Ministry of Education, Science, Culture and Sport (project MNT-Era-Net n-POSSCOG). The funding sources were not involved in study design; in the collection, analysis, and interpretation of data; in the writing of the report; or in the decision to submit the article for publication.

\section{Author contributions}

All authors contributed toward data analysis, drafting and critically revising the paper, gave final approval of the version to be published, and agree to be accountable for all aspects of the work.

\section{Disclosure}

The authors report no conflicts of interest in this work.

\section{References}

1. Kargarzadeh H, Mariano M, Gopakumar D, et al. Advances in cellulose nanomaterials. Cellulose. 2018;25(4):2151-2189.

2. Lin N, Dufresne A. Nanocellulose in biomedicine: Current status and future prospect. Eur Polym J. 2014;59:302-325.

3. Wen X, Zheng Y, Wu J, et al. Immobilization of collagen peptide on dialdehyde bacterial cellulose nanofibers via covalent bonds for tissue engineering and regeneration. Int J Nanomedicine. 2015;10:4623.

4. Novotna K, Havelka P, Sopuch T, et al. Cellulose-based materials as scaffolds for tissue engineering. Cellulose. 2013;20(5):2263-2278.

5. Hakkarainen T, Koivuniemi R, Kosonen M, et al. Nanofibrillar cellulose wound dressing in skin graft donor site treatment. J Control Release. 2016;244(Pt B):292-301.

6. Janjic M, Pappa F, Karagkiozaki V, Gitas C, Ktenidis K, Logothetidis S. Surface modification of endovascular stents with rosuvastatin and heparin-loaded biodegradable nanofibers by electrospinning. Int $J$ Nanomedicine. 2017;12:6343-6355. 
7. Gorgieva S, Girandon L, Kokol V. Mineralization potential of cellulosenanofibrils reinforced gelatine scaffolds for promoted calcium deposition by mesenchymal stem cells. Mater Sci Eng C Mater Biol Appl. 2017; $73: 478-489$.

8. Ding Q, Xu X, Yue Y, et al. Nanocellulose-mediated electroconductive self-healing hydrogels with high strength, plasticity, viscoelasticity, stretchability, and biocompatibility toward multifunctional applications. ACS Appl Mater Interfaces. 2018;10(33):27987-28002.

9. Čolić M, Mihajlović D, Mathew A, Naseri N, Kokol V. Cytocompatibility and immunomodulatory properties of wood based nanofibrillated cellulose. Cellulose. 2015;22(1):763-778.

10. Tibolla H, Pelissari FM, Martins JT, Vicente AA, Menegalli FC. Cellulose nanofibers produced from banana peel by chemical and mechanical treatments: Characterization and cytotoxicity assessment Food Hydrocoll. 2018;75:192-201.

11. Märtson M, Viljanto J, Hurme T, Laippala P, Saukko P. Is cellulose sponge degradable or stable as implantation material? An in vivo subcutaneous study in the rat. Biomaterials. 1999;20(21):1989-1995.

12. Saito T, Kimura S, Nishiyama Y, Isogai A. Cellulose nanofibers prepared by TEMPO-mediated oxidation of native cellulose. Biomacromolecules. 2007;8(8):2485-2491.

13. O’Brien FJ. Biomaterials \& scaffolds for tissue engineering. Mater Today. 2011;14(3):88-95.

14. Kollar P, Závalová V, Hošek J, et al. Cytotoxicity and effects on inflammatory response of modified types of cellulose in macrophage-like THP-1 cells. Int Immunopharmacol. 2011;11(8):997-1001.

15. Vartiainen J, Pöhler T, Sirola K, et al. Health and environmental safety aspects of friction grinding and spray drying of microfibrillated cellulose. Cellulose. 2011;18(3):775-786.

16. Azuma K, Osaki T, Ifuku S, et al. Suppressive effects of cellulose nanofibers - made from adlay and seaweed - on colon inflammation in an inflammatory bowel-disease model. Bioactive Carbohydrates and Dietary Fibre. 2013;2(1):65-72.

17. Dobrovolskaia MA, Mcneil SE. Immunological properties of engineered nanomaterials. Nat Nanotechnol. 2007;2(8):469-478.

18. Aldinucci A, Turco A, Biagioli T, et al. Carbon nanotube scaffolds instruct human dendritic cells: modulating immune responses by contacts at the nanoscale. Nano Lett. 2013;13(12):6098-6105.

19. Gad M, Ravn P, Søborg DA, Lund-Jensen K, Ouwehand AC, Jensen SS. Regulation of the IL-10/IL-12 axis in human dendritic cells with probiotic bacteria. FEMS Immunol Med Microbiol. 2011;63(1): 93-107.

20. Steinman RM, Hawiger D, Nussenzweig MC. Tolerogenic dendritic cells. Annu Rev Immunol. 2003;21(1):685-711.

21. Nich C, Takakubo Y, Pajarinen J, et al. Macrophages-Key cells in the response to wear debris from joint replacements. J Biomed Mater Res A. 2013;101(10):3033-3045.

22. Luger D, Silver PB, Tang J, et al. Either a Th17 or a Th1 effector response can drive autoimmunity: conditions of disease induction affect dominant effector category. J Exp Med. 2008;205(4):799-810.

23. Cvetkovic J, Sofronic-Milosavljevic L, Ilic N, Gnjatovic M, Nagano I, Gruden-Movsesijan A. Immunomodulatory potential of particular Trichinella spiralis muscle larvae excretory-secretory components Int J Parasitol. 2016;46(13-14):833-842.

24. Dokić J, Tomić S, Marković M, Milosavljević P, Colić M. Mesenchymal stem cells from periapical lesions modulate differentiation and functional properties of monocyte-derived dendritic cells. Eur J Immunol. 2013;43(7):1862-1872.

25. Ilarregui JM, Croci DO, Bianco GA, et al. Tolerogenic signals delivered by dendritic cells to T cells through a galectin-1-driven immunoregulatory circuit involving interleukin 27 and interleukin 10. Nat Immunol. 2009;10(9):981-991.

26. Raker VK, Domogalla MP, Steinbrink K. Tolerogenic dendritic cells for regulatory T cell induction in man. Front Immunol. 2015;6:569.

27. van Brussel I, Lee WP, Rombouts M, et al. Tolerogenic dendritic cell vaccines to treat autoimmune diseases: can the unattainable dream turn into reality? Autoimmun Rev. 2014;13(2):138-150.
28. Li H, Shi B. Tolerogenic dendritic cells and their applications in transplantation. Cell Mol Immunol. 2015;12(1):24-30.

29. Tomić S, Rudolf R, Brunčko M, Anžel I, Savić V, Colić M. Response of monocyte-derived dendritic cells to rapidly solidified nickel-titanium ribbons with shape memory properties. Eur Cell Mater. 2012;23:58-80.

30. Dai Z, Zhang S, Xie Q, et al. Natural CD8+CD122+ T cells are more potent in suppression of allograft rejection than $\mathrm{CD} 4+\mathrm{CD} 25+$ regulatory T cells. Am J Transplant. 2014;14(1):39-48.

31. Tomić S, Kokol V, Mihajlović D, Mirčić A, Čolić M. Native cellulose nanofibrills induce immune tolerance in vitro by acting on dendritic cells. Sci Rep. 2016;6:31618.

32. ISO 10304-1. Water quality - Determination of dissolved anions by liquid chromatography of ions. Part 1: Determination of bromide, chloride, fluoride, nitrate, nitrite, phosphate and sulfate. Vol 10304-1. International Standards Organisation; 2007. Available from: https:// www.iso.org/standard/46004.html. Accessed October 16, 2018.

33. Pradhan S, Pokhrel MR. Spectrophotometric determination of phosphate in sugarcane juice, fertilizer, detergent and water samples by molybdenum blue method. Scientific World. 2013;11(11):58-62.

34. Tomić S, Janjetović K, Mihajlović D, et al. Graphene quantum dots suppress proinflammatory $\mathrm{T}$ cell responses via autophagy-dependent induction of tolerogenic dendritic cells. Biomaterials. 2017;146: 13-28.

35. Relloso M, Puig-Kröger A, Pello OM, et al. DC-SIGN (CD209) expression is IL-4 dependent and is negatively regulated by IFN, TGF-beta, and anti-inflammatory agents. J Immunol. 2002;168(6):2634-2643.

36. Tomić S, Đokić J, Vasilijić S, et al. Size-dependent effects of gold nanoparticles uptake on maturation and antitumor functions of human dendritic cells in vitro. PLoS One. 2014;9(5):e96584.

37. Kalinski P, Wieckowski E, Muthuswamy R, de Jong E. Generation of stable Th1/CTL-, Th2-, and Th17-inducing human dendritic cells. Dendritic Cell Protocols. 2010:117-133.

38. Murphy FA, Schinwald A, Poland CA, Donaldson K. The mechanism of pleural inflammation by long carbon nanotubes: interaction of long fibres with macrophages stimulates them to amplify pro-inflammatory responses in mesothelial cells. Part Fibre Toxicol. 2012;9(1):8.

39. Chomarat P, Banchereau J, Davoust J, Palucka AK. IL-6 switches the differentiation of monocytes from dendritic cells to macrophages. Nat Immunol. 2000;1(6):510-514.

40. Magerus-Chatinet A, Stolzenberg MC, Loffredo MS, et al. FAS-L, IL-10, and double-negative $\mathrm{CD}^{-}{ }^{-} \mathrm{CD} 8^{-}$TCR alpha/beta+ $\mathrm{T}$ cells are reliable markers of autoimmune lymphoproliferative syndrome (ALPS) associated with FAS loss of function. Blood. 2009;113(13):3027-3030.

41. White AM, Wraith DC. Tr1-Like T Cells - An Enigmatic Regulatory T Cell Lineage. Front Immunol. 2016;7(Suppl 1):355.

42. Vlad G, Cortesini R, Suciu-Foca N. CD8+ T suppressor cells and the ILT3 master switch. Hum Immunol. 2008;69(11):681-686.

43. Bahri R, Bollinger A, Bollinger T, Orinska Z, Bulfone-Paus S. Ectonucleotidase CD38 demarcates regulatory, memory-like CD8+ T cells with IFN- $\gamma$-mediated suppressor activities. PLoS One. 2012;7(9): e45234.

44. Stroopinsky D, Avivi I, Rowe JM, Avigan D, Katz T. Allogeneic induced human FOXP3(+)IFN-gamma(+) T cells exhibit selective suppressive capacity. Eur J Immunol. 2009;39(10):2703-2715.

45. Xu Z, Ho S, Chang CC, et al. Molecular and cellular characterization of human CD8 T suppressor cells. Front Immunol. 2016;7:549.

46. Cernadas M, Lu J, Watts G, Brenner MB. CD1a expression defines an interleukin-12 producing population of human dendritic cells. Clin Exp Immunol. 2009;155(3):523-533.

47. Kvistborg P, Boegh M, Pedersen AW, Claesson MH, Zocca MB. Fast generation of dendritic cells. Cell Immunol. 2009;260(1):56-62.

48. Pavlović B, Tomić S, Đokić J, et al. Fast dendritic cells matured with Poly (I: C) may acquire tolerogenic properties. Cytotherapy. 2015; 17(12):1763-1776.

49. Gregori S, Tomasoni D, Pacciani V, et al. Differentiation of type 1 $\mathrm{T}$ regulatory cells $(\mathrm{Tr} 1)$ by tolerogenic DC-10 requires the IL-10 dependent ILT4/HLA-G pathway. Blood. 2010;116(6):935-944. 
50. Gu Y, Yang J, Ouyang X, et al. Interleukin 10 suppresses Th17 cytokines secreted by macrophages and T cells. Eur J Immunol. 2008;38(7): 1807-1813.

51. Gorelik L, Flavell RA. Transforming growth factor-beta in T-cell biology. Nat Rev Immunol. 2002;2(1):46-53.

52. Gerosa F, Baldani-Guerra B, Lyakh LA, et al. Differential regulation of interleukin 12 and interleukin 23 production in human dendritic cells. J Exp Med. 2008;205(6):1447-1461.

53. Damsker JM, Hansen AM, Caspi RR. Th1 and Th17 cells. Ann N Y Acad Sci. 2010;1183(1):211-221.

54. Liu H, Rohowsky-Kochan C. Interleukin-27-mediated suppression of human Th17 cells is associated with activation of STAT1 and suppressor of cytokine signaling protein 1. J Interferon Cytokine Res. 2011; 31(5):459-469.

55. Macdonald AS, Maizels RM. Alarming dendritic cells for Th2 induction. J Exp Med. 2008;205(1):13-17.

56. Rosenblum MD, Way SS, Abbas AK. Regulatory T cell memory. Nat Rev Immunol. 2016;16(2):90-101.

57. Vignali DA, Collison LW, Workman CJ. How regulatory T cells work. Nat Rev Immunol. 2008;8(7):523-532.

58. Penna G, Roncari A, Amuchastegui S, et al. Expression of the inhibitory receptor ILT3 on dendritic cells is dispensable for induction of CD4+Foxp3+ regulatory T cells by 1,25-dihydroxyvitamin D3. Blood. 2005;106(10):3490-3497.

59. Groux H, O’Garra A, Bigler M, et al. A CD4+ T-cell subset inhibits antigen-specific T-cell responses and prevents colitis. Nature. 1997; 389(6652):737-742

60. Jin JO, Han X, Yu Q. Interleukin-6 induces the generation of IL-10producing $\operatorname{Tr} 1$ cells and suppresses autoimmune tissue inflammation. $J$ Autoimmun. 2013;40:28-44.

61. Pot C, Jin H, Awasthi A, et al. Cutting edge: IL-27 induces the transcription factor c-Maf, cytokine IL-21, and the costimulatory receptor ICOS that coordinately act together to promote differentiation of IL-10producing Tr1 cells. J Immunol. 2009;183(2):797-801.

62. Le Rond S, Le Maoult J, Créput C, et al. Alloreactive CD4+ and CD8+ $\mathrm{T}$ cells express the immunotolerant HLA-G molecule in mixed lymphocyte reactions: in vivo implications in transplanted patients. Eur J Immunol. 2004;34(3):649-660.

63. Shi Z, Okuno Y, Rifa'i M, et al. Human CD8+CXCR3+ T cells have the same function as murine CD8+CD122+ Treg. Eur J Immunol. 2009;39(8):2106-2119.

64. Churlaud G, Pitoiset F, Jebbawi F, et al. Human and Mouse CD8(+) CD25(+)FOXP3(+) Regulatory T Cells at Steady State and during Interleukin-2 Therapy. Front Immunol. 2015;6:171.
65. Liu J, Chen D, Nie GD, Dai Z. CD8(+)CD122(+) T-Cells: A Newly Emerging Regulator with Central Memory Cell Phenotypes. Front Immunol. 2015;6:494

66. Kmieciak M, Gowda M, Graham L, et al. Human T cells express CD25 and Foxp3 upon activation and exhibit effector/memory phenotypes without any regulatory/suppressor function. J Transl Med. 2009;7(1):89.

67. Zheng J, Liu Y, Qin G, et al. Efficient induction and expansion of human alloantigen-specific CD8 regulatory $\mathrm{T}$ cells from naive precursors by CD40-activated B cells. J Immunol. 2009;183(6):3742-3750.

68. Li XL, Ménoret S, Bezie S, et al. Mechanism and localization of CD8 regulatory $\mathrm{T}$ cells in a heart transplant model of tolerance. J Immunol. 2010;185(2):823-833.

69. Koch SD, Uss E, van Lier RA, Ten Berge IJ. Alloantigen-induced regulatory CD8+CD103+ T cells. Hum Immunol. 2008;69(11):737-744.

70. Caspi RR. Immunotherapy of autoimmunity and cancer: the penalty for success. Nat Rev Immunol. 2008;8(12):970-976.

71. Sofronic-Milosavljevic LJ, Radovic I, Ilic N, Majstorovic I, Cvetkovic J, Gruden-Movsesijan A. Application of dendritic cells stimulated with Trichinella spiralis excretory-secretory antigens alleviates experimental autoimmune encephalomyelitis. Med Microbiol Immunol. 2013;202(3):239-249.

72. Collins A, Warrington A, Taylor KA, Svitkina T. Structural organization of the actin cytoskeleton at sites of clathrin-mediated endocytosis. Curr Biol. 2011;21(14):1167-1175.

73. Schulz AM, Stutte S, Hogl S, et al. Cdc42-dependent actin dynamics controls maturation and secretory activity of dendritic cells. J Cell Biol. 2015;211(3):553-567.

74. Guo Y, Feinberg H, Conroy E, et al. Structural basis for distinct ligand-binding and targeting properties of the receptors DC-SIGN and DC-SIGNR. Nat Struct Mol Biol. 2004;11(7):591-598.

75. VajgerSvajger U, Obermajer N, Anderluh M, Kos J, Jeras M. DC-SIGN ligation greatly affects dendritic cell differentiation from monocytes compromising their normal function. J Leukoc Biol. 2011;89(6): 893-905.

76. di Cio S, Gautrot JE. Cell sensing of physical properties at the nanoscale: Mechanisms and control of cell adhesion and phenotype. Acta Biomater. 2016;30:26-48.

77. Klunk WE, Mcclure RJ, Xu C-J, Pettegrew JW. Structural determinants of activity at the GABAB receptor. Mol Chem Neuropathol. 1995; 26(1):15-30.

78. Duthey B, Hübner A, Diehl S, Boehncke S, Pfeffer J, Boehncke WH. Anti-inflammatory effects of the GABA(B) receptor agonist baclofen in allergic contact dermatitis. Exp Dermatol. 2010;19(7):661-666. 


\section{Supplementary materials}
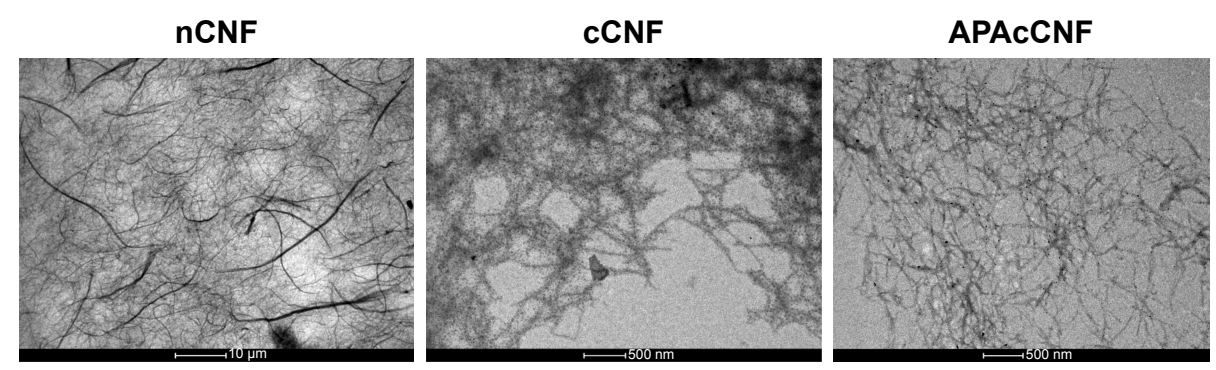

Figure SI TEM analysis of CNF samples.

Abbreviations: APA, 3-aminopropylphosphoric acid; APAc, APA-functionalized; c, carboxylated; CNF, cellulose nanofibrils; n, native; TEM, transmission electron microscopy.

A
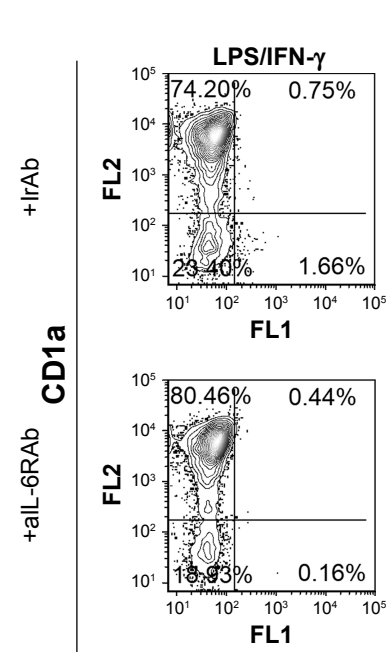

\section{CD14}

C
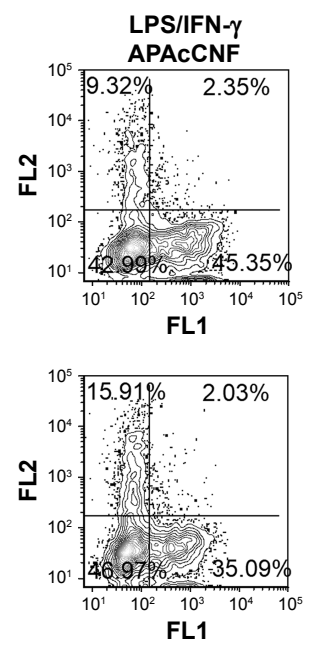

FL1

B
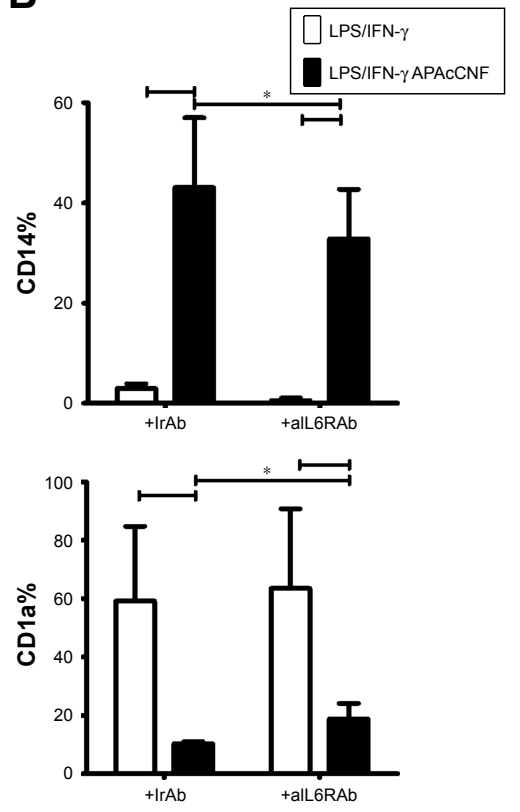

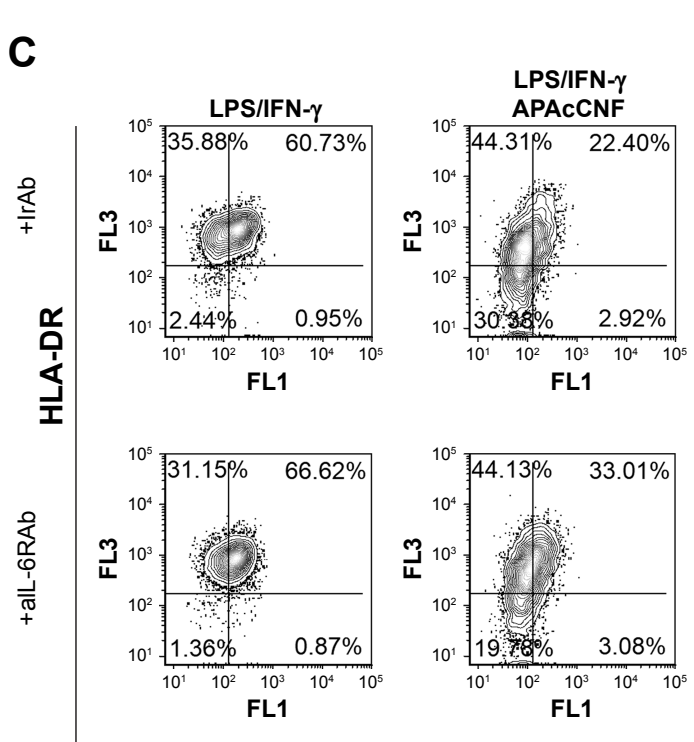

CD83

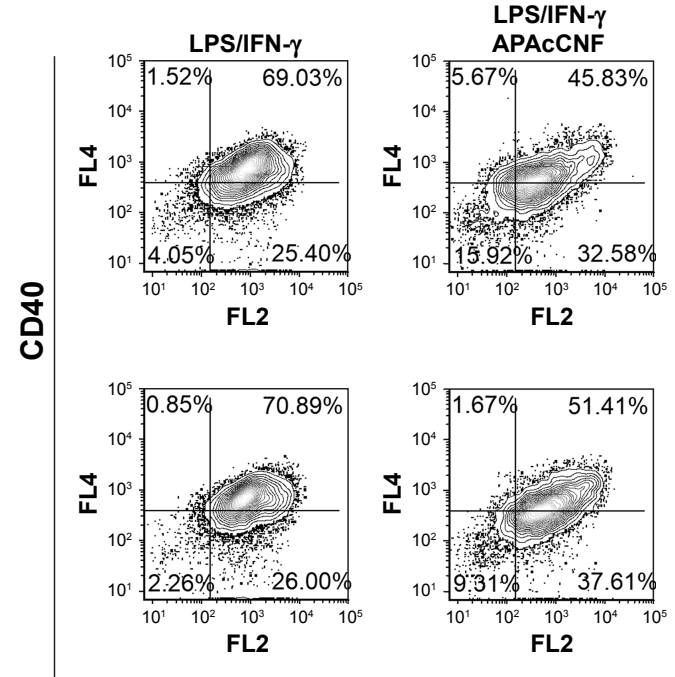

CD86

Figure S2 Role of IL-6 in differentiation and maturation of DC treated with APAcCNF.

Notes: (A) A representative analysis of CDIa/CDI4 expression on DC cultivated with APAcCNF in the presence of alL-6R or isotype control Abs is shown and, (B) the summarized results are presented as mean \pm SD of three independent experiments. (C) A representative analysis of DC phenotype after 16 hours of stimulation with LPS/ IFN- $\gamma$ is shown, out of three experiments with similar results. $* P<0.05$ as indicated (RM ANOVA).

Abbreviations: alL-6RAb, anti-IL-6 receptor antibody (tocilizumab); APA, 3-aminopropylphosphoric acid; APAc, APA-functionalized; c, carboxylated; CNF, cellulose nanofibrils; DC, dendritic cells; HLA, human leukocyte antigen; IFN, interferon; IrAb, isotype control antibody; LPS, lipopolysaccharide; n, native; RM, repeated measures. 


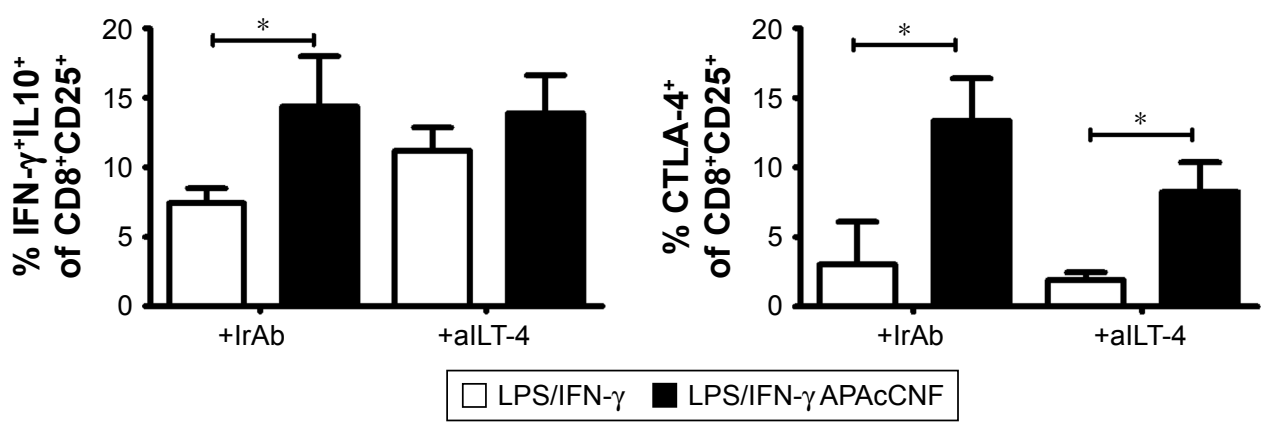

Figure S3 ILT4-dependent mechanisms of APACCNF-DC.

Notes: The summarized data on phenotype of MACS-sorted CD8 ${ }^{+} \mathrm{CD} 25^{+} \mathrm{T}$ cells co-cultivated with DC in the presence or absence of blocking anti-ILT4 Ab data from four different experiments is shown as mean $\pm S D$. $* P<0.05$ as indicated (RM ANOVA).

Abbreviations: Ab, antibody; alLT-4, blocking anti-ILT-4 antibody; APA, 3-aminopropylphosphoric acid; APAc, APA-functionalized; CNF, cellulose nanofibrils; CTLA, cytotoxic T-lymphocyte-associated protein; DC, dendritic cells; IFN, interferon; ILT, immunoglobulin-like transcript; +IrAb, irrelevant antibody; LPS, lipopolysaccharide; MACS, magnetic-activated cell sorting; RM, repeated measures.

\section{Publish your work in this journal}

The International Journal of Nanomedicine is an international, peerreviewed journal focusing on the application of nanotechnology in diagnostics, therapeutics, and drug delivery systems throughout the biomedical field. This journal is indexed on PubMed Central, MedLine, CAS, SciSearch $®$, Current Contents ${ }^{\circledR} /$ Clinical Medicine,
Journal Citation Reports/Science Edition, EMBase, Scopus and the Elsevier Bibliographic databases. The manuscript management system is completely online and includes a very quick and fair peer-review system, which is all easy to use. Visit http://www.dovepress.com/ testimonials.php to read real quotes from published authors. 